\title{
Recommendations and Comments on the Draft Vertical Merger Guidelines
}

Jonathan B. Baker

American University Washington College of Law, jbaker@wcl.american.edu

Nancy L. Rose

Massachusetts Institute of Technology, Department of Economics, nrose@mit.edu

Steven C. Salop

Georgetown University Law Center, salop@law.georgetown.edu

Fiona Scott Morton

Yale School of Management, fiona.scottmorton@yale.edu

This paper can be downloaded free of charge from:

https://scholarship.law.georgetown.edu/facpub/2239

https://ssrn.com/abstract=3543736

Jonathan B. Baker, Nancy L. Rose, Steven C. Salop \& Fiona Scott Morton, Recommendations and Comments on the Draft Vertical Merger Guidelines (Feb. 24, 2020)

This open-access article is brought to you by the Georgetown Law Library. Posted with permission of the author. Follow this and additional works at: https://scholarship.law.georgetown.edu/facpub

Part of the Antitrust and Trade Regulation Commons, Business Organizations Law Commons, Corporate Finance Commons, Law and Economics Commons, and the Securities Law Commons 


\title{
Recommendations and Comments on the Draft Vertical Merger Guidelines
}

\author{
Jonathan B. Baker* \\ Nancy L. Rose \\ Steven C. Salop \\ Fiona Scott Morton
}

February 24, 2020

\section{Table of Contents}

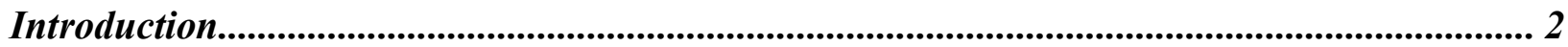

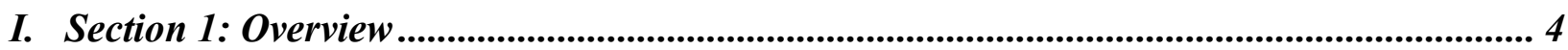

II. Section 2: Market Definition and Related Products......................................................... 6

III. Section 3: Market Participants, Market Shares, And Market Concentration .................... 7

A. The Related Product's Low Share of Output Poorly Measures Lack of Competitive Concerns

B. The 20-20 Share-Based Safe Harbor Screen is a Defective Measure of Unlikely Competitive Harms ....................................................................................................................................................... 11

C. Is a Safe Harbor Even Needed and If So, How Should It Be Structured? .................................16

D. Anticompetitive Presumptions Should be Adopted ................................................................................ 18

IV. Section 4: Evidence of Adverse Competitive Effects ............................................................ 20

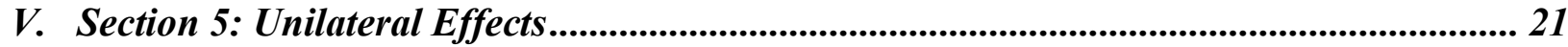

A. The Analysis of Foreclosure and Raising Rivals' Costs Should be Clarified ............................. 21

B. Currently Omitted Competitive Concerns Should be Included ...................................................24

C. The Profitability Test Should Not Refer to Pre-Merger Profitability.......................................... 27

D. Quantification Should Not be Required ...............................................................................................29

VI. Section 6: Elimination of Double Marginalization ........................................................... 30

A. EDM Should Be Treated in the Same Way as Other Efficiencies ...............................................30

B. Erroneous Arguments for Treating EDM as Part of Competitive Harm Should Not Be

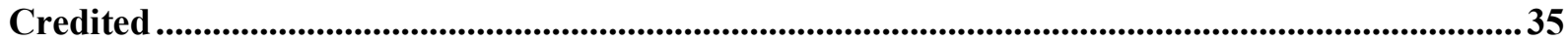

VII. Section 7: Coordinated Effects ................................................................................ 38

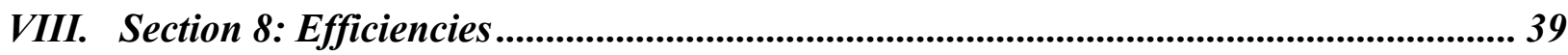

IX. Remedy ............................................................................................................................ 40

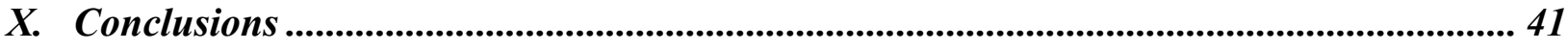




\section{$\underline{\text { Introduction }}$}

We are pleased to provide recommendations and comments on the Draft Vertical Merger Guidelines ("dVMGs"). ${ }^{1}$ We commend the agencies for updating the 1984 non-horizontal merger guidelines by recognizing the substantial advances in economic thinking about vertical mergers in the thirty-five years since the 1984 guidelines were issued.

The dVMGs generally apply the modern economic framework for analyzing vertical mergers. They recognize that there can be anticompetitive harms from unilateral or coordinated conduct. They cover both input and customer foreclosure, and recognize the fact that distribution services can be viewed as an input. With respect to input foreclosure, they recognize various ways in which foreclosure can occur, including refusals to deal (i.e., total withholding), raising rivals' costs, and increased bargaining power, all of which appear in the economics literature.

The dVMGs do not make the old errors of saying that foreclosure is illusory, or that vertical mergers are typically procompetitive, irrespective of market structure. They properly decline to adopt an explicit procompetitive presumption. The agencies have made the correct decisions not to credit the erroneous claim that there is typically only a single monopoly profit, and not to adopt an aggregate welfare (total efficiency) standard for enforcement. These misguided ideas were properly excluded.

Our comments offer suggestions for improvement to the final VMGs that are rooted in the economics literature and decision theory. As a general matter, we recommend that the economic analysis and potential evidence be spelled out in more detail. This would provide beneficial and practical information, and reduce the potential for confusion.

We are concerned that certain features of the dVMGs raise a serious prospect of false negatives and under-enforcement. There are gaps in the anticompetitive harms covered. These gaps might

\footnotetext{
* The authors' academic affiliations and agency positions are: Baker (Research Professor of Law, American University Washington College of Law; Chief Economist, Federal Communications Commission (2009-2011); Director, Bureau of Economics, Federal Trade Commission (1995-1998)); Rose (Charles P. Kindleberger Professor of Applied Economics and Department Head, Massachusetts Institute of Technology; Deputy Assistant Attorney General for Economic Analysis, U.S. Department of Justice (2014-2016)); Salop (Professor of Economics and Law, Georgetown University Law Center; Associate Director for Special Projects, Bureau of Economics, Federal Trade Commission (1980 -1981)); and Scott-Morton (Theodore Nierenberg Professor of Economics at the Yale School of Management; Deputy Assistant Attorney General for Economic Analysis, U.S. Department of Justice (2011-2012)). All opinions are our own.

${ }^{1}$ U.S. Dep't of Justice \& Fed. Trade Comm'n, Draft Vertical Merger Guidelines, Released for Public Comment (January 10, 2020) [hereinafter dVMGs], https://www.ftc.gov/system/files/documents/public_statements/1561715/p810034verticalmergerguideline sdraft.pdf.
} 
suggest lesser concerns from the omitted possibilities or might otherwise lead the agencies to overlook or minimize them. In addition, the dVMGs set an excessive burden on the agencies. Because these guidelines may influence the courts, as the dVMGs themselves recognize, these excessive burdens also will tend to raise the burdens faced by the agencies and private plaintiffs in litigation.

Aside from the gaps, our greatest concerns involve four issues: (i) the treatment of the elimination of double marginalization ("EDM"), particularly that the dVMGs appear inappropriately to make proof of cognizability part of the agencies burden and that they appear to inappropriately treat the merging firm's failure to have eliminated double marginalization premerger as proof that the merger would lead to EDM and that the post-merger EDM would be merger-specific; (ii) the seemingly arbitrary and inappropriately permissive safe harbor; (iii) the inappropriate (though perhaps unintended) apparent requirement that harms be quantified; and (iv) the inappropriate (though perhaps unintended) apparent requirement that the agencies show that foreclosure would not have been profitable before the merger. We are concerned that these features of the dVMGs will lead to under-enforcement and false negatives (including underdeterrence).

In these comments, we suggest a number of revisions to address these problems and assist the agencies in the adoption of an enforcement policy that will protect consumers from anticompetitive conduct in $21^{\text {st }}$ century markets and provide greater guidance to practitioners and agency staff. ${ }^{2}$ Our suggestions are designed to reduce the incidence of false negatives, but without materially increasing false positives. If our suggestions are adopted, only a subset of vertical mergers would be subject to close scrutiny and the agencies (or private plaintiffs) would still be required to demonstrate competitive harm. The merging firms should have no difficulty proving the matters for which they have the burden, if the underlying reality supports their argument.

We recognize that our comments are extensive. Their length is necessary to spell out our concerns, carry out analysis of those concerns rather than making unsupported conclusory statements, and provide our recommended solutions in sufficient detail to be helpful to the drafters in revising the dVMGs.

We organize our comments around the various sections of the dVMGs.

\footnotetext{
${ }^{2}$ Many of comments and suggestions flow from our earlier writings, in particular, Jonathan B. Baker, Nancy L. Rose, Steven C. Salop \& Fiona Scott Morton, Five Principles for Vertical Merger Enforcement Policy, 33 AnTITRUST 12 (2019); Steven C. Salop, Invigorating Vertical Merger Enforcement, 127 YALE L.J. 1962 (2018).
} 


\section{Section 1: Overview}

The dVMGs explain that they are to be read in the conjunction with the Horizontal Merger Guidelines ("HMGs"). ${ }^{3}$ This makes sense as a matter of both economics and policy. The basic economic tools for evaluating the competition and the effects of mergers are the same for both horizontal and vertical mergers. For example, foreclosure creates anticompetitive horizontal effects similar to those of a horizontal merger. Coordinated effects also are similar. In addition, the HMGs also reflect economics "best practices" for analyzing certain issues.

We have several specific suggestions for this section of the dVMGs.

First, we suggest that it be made clear that while these mergers may be vertical, the competitive concern is horizontal. For example, by foreclosing competitors of the downstream merging firm and raising their costs, a vertical merger can cause those rivals to reduce their output and raise their prices, just as they might from a horizontal merger with the downstream merging firm. ${ }^{4}$

In this regard, it also sometimes is argued that a vertical merger does not inherently eliminate any competition, unlikely a horizontal merger. However, while this observation might appear correct in a superficial or formal sense, the economic analysis of input foreclosure shows why it is not economically correct. It ignores the fact that in the pre-merger market, the (future) upstream merging firm has a role in "supporting" competition in the downstream market by rivals of its (future) downstream merger partner. By providing inputs to these rivals (in competition with other upstream firms), the future upstream merging firm facilitates and increases competition in the downstream market. In this sense, the (future) upstream merging firm has some "indirect control" over the ability of the downstream rivals to compete with the (future) downstream merging firm. ${ }^{5}$ When the merger then leads to upstream merging firm to take account of the diversion to the downstream merging firm, it has a direct (first-round) incentive to reduce or eliminate this support of downstream competitors and competition. For

${ }^{3}$ U.S. DEP'T OF JUSTICE \& Fed. TRADE COMM'N HORIZONTAL MERGER Guidelines (2010) [hereinafter HMGs], https://www.ftc.gov/sites/default/files/attachments/merger-review/100819hmg.pdf.

${ }^{4}$ See Jonathan B. Baker, Exclusion as a Core Competition Concern, 78 ANTITRUST L.J. 527, 556-58 (2013) (explaining that exclusionary conduct can harm competition by creating an involuntary or coerced cartel).

${ }^{5}$ To illustrate, consider the simple but extreme case in which, the pre-merger upstream merging firm is supplying inputs to some rivals of the downstream merging firm who were unable to engage in any input substitution among the upstream firms. By raising its input price after merger, the upstream merging firm raises the costs of the downstream firms it supplies, which allows it effectively to control their outputs and pricing incentives. Thus, the vertical merger would allow the merged firm to control the output and prices of these downstream competitors. In this sense, the merger creates an indirect horizontal consolidation between the downstream merging firm and the foreclosed rival firms. For further details, see Serge Moresi \& Steven C. Salop, Quantifying the Increase in "Effective Concentration" from Vertical Mergers that Raise Input Foreclosure Concerns: Comment on the Draft Vertical Merger Guidelines (February 24, 2020) (hereinafter, Moresi \& Salop (Comment)). 
this reason, there is an inherent horizontal element to a vertical merger that might lead to input foreclosure.

Second, it would be useful to point out that the effect of a merger "may be substantially to lessen competition" in the meaning of Section 7 of the Clayton Act if there is a "reasonable probability" that it will have anticompetitive effects. ${ }^{6}$ This is consistent with the "incipiency" concerns of Section 7, which amount to the concern to prevent false negatives and under-deterrence. Endorsing this standard of analysis also is important to clearly dispel the view that vertical mergers somehow deserve a more permissive enforcement standard.

Third, we suggest making it clear in this section that these guidelines also apply to the analysis of complementary product mergers. Section 8 of the dVMGs makes the point that vertical mergers "combine complementary economic functions." However, footnote 2 could be read to suggest that only strictly vertical mergers are covered by the dVMGs. While the quantitative modeling of complementary product mergers may differ in small ways, the basic concerns and methodology are similar.

Limiting the application of Vertical Merger Guidelines ("VMGs") solely to clearly "vertical" relationships excludes many merging firms where a similar analysis should apply but where it may be difficult to say which firm is "closer to final consumers." If neither firm's product or service is "closer to final consumers," then, according to footnote 2 , the firms are not operating "at different stages of the same supply chain" and, in consequence, their merger would not be called vertical and the VMGs would not govern how they are analyzed.

In the modern economy, however, it is common to have mergers of firms providing complements where it is not obvious which stage is closer to consumers, so the merger would not necessarily be characterized as vertical - and yet a vertical merger analysis should apply. For example, suppose an Internet service provider ("ISP") buys a programming company that offers a video streaming channel directly to consumers. The consumer purchases Internet service from the ISP and contracts directly with the programming company for the video channel. Is the ISP or the channel closer to consumers? Or, suppose a smartphone operating system provider acquires an app that charges consumers monthly. If the smartphone operating system provider does the monthly billing, does that make it the party closer to final consumers even though the app provides the service directly to consumers? In addition, various firms in the same industry may differ in their approach. One ISP might buy programming and resell it while another may sell unbundled distribution and allow consumers to buy the programming directly. It would not make sense to have the final VMGs govern mergers by the first ISP but not the other. Thus, we recommend that the description of the guidelines be broadened to include complementary

\footnotetext{
${ }^{6}$ See Proposed Conclusions of Law of the United States at $9 \uparrow 14-16$, United States v. AT\&T, Inc., 916 F.3d 1029 (D.C. Cir. 2019) (holding that the government must show "that the proposed merger is likely to substantially lessen competition, which encompasses a concept of 'reasonable probability',') (emphasis omitted).
} 
product mergers as well as strictly vertical mergers, including complementary product mergers that also might be viewed as acquisitions of potential entrants and potential competitors.

Fourth, we are concerned that applying the "closer to final consumers" definition to the use of the terms "upstream" and "downstream" can lead to significant confusion or even error when the vertical merger involves a manufacturer and a distributor. While a distributor is closer to the consumer in some literal sense, as an economic matter, the distributor can equally be seen as providing an input (i.e., distribution services) to the manufacturer. For example, by foreclosing rival manufacturers from that input, the merging manufacturer can raise the costs of rival manufacturers. This is why Sylvania referred to the "cost of distribution." In fact, Example 6 in the dVMGs makes this point.

\section{Section 2: Market Definition and Related Products}

As a strictly economic matter, vertical mergers can affect competition in both the upstream and downstream markets. The final VMGs should clarify that where competition would potentially be harmed both upstream and downstream, the agencies will analyze both possibilities.

In analyzing a potential competitive concern, the dVMGs formally define a relevant market that is comprised of the products and locations where the ultimate competitive harm occurs, but they do not define a market involving the products and locations at the other vertical level. In the case of input foreclosure, for example, the relevant market is the output market. The input is denoted a "related product" for which a formal market definition is not required.

We agree that it may not be necessary to formally define a "related product" market for the purpose of enforcing Section 7 of the Clayton Act. That requirement could make the analysis more complex without improving the economic analysis. However, it may be necessary to understand in detail the nature of the related product, how it is used by participants in the relevant market, and how its producers or sellers compete. There, the analysis of the "related product" should include any concepts or facts needed to assess competitive effects. (Some of these may also come up in market definition, such as the extent the relevant buyers can substitute across products, but other concepts or facts may be considered, and this analysis need not require defining a relevant market.) It would be useful for the VMGs to explain this point.

In the input foreclosure case, for example, it will be necessary to understand what inputs are included in the "related product" category when there is actual input substitution among the suppliers, and understand the nature of potential input substitution, in order to evaluate the ability of the merged firm to harm competition by altering the terms at which it sells the related product input to downstream rivals. Analysis will be needed to understand whether price increases by the merging firm that produces the "related product" will lead to accommodating price increases

\footnotetext{
${ }^{7}$ Continental T.V., Inc. v. GTE Sylvania, Inc., 433 U.S. 36, 56 n.24 (1977).
} 
by its competitors that could exacerbate the anticompetitive potential of a price increase by the upstream merging firm. It will also be necessary to measure the share of output accounted for by the related product, and thus for the final VMGs to discuss more fully how to do so (as we indicate below in our comments on Section 3$)^{8}$

The market definition analysis in the dVMGs is appropriately assumed to follow the approach in the HMGs, but it would be helpful for the final VMGs to discuss some distinctive market definition issues flowing from the vertical merger context.

First, a vertical merger may occur in a market where the merged firm is already is vertically integrated or where it will compete with one or more firms that are already vertically integrated. In such a case, for the reasons given in footnote 4 of the HMGs, the market definition exercise may account for the incentives of a hypothetical monopolist (or hypothetical cartel) that is vertically integrated.

Second, it is possible, particularly when reviewing vertical acquisitions by dominant firms, that the current price is highly supracompetitive, and the competitive concern is that a vertical merger will prevent prices from falling by reducing the likelihood of increased competition. In this situation, the current (pre-merger) world should not be used as the "but-for world" pricing benchmark for the hypothetical monopolist test; a lower price resulting from increased competition is the appropriate benchmark, for the same reason that the HMGs suggest using a lower price when prices may fall absent the merger due to the breakdown of pre-merger coordination.

\section{Section 3: Market Participants, Market Shares, And Market Concentration}

We will comment in detail on four related issues that raise significant concerns about this section: (i) the use of the "share of output" measure for the related product; (ii) the safe harbor screen that is triggered by a market share of less than $20 \%$ in the primary market and a less than $20 \%$ "share of output" of the related product, which we will term the " $20-20$ " screen; (iii) whether a safe harbor is even needed, and if so, whether it should be based on concentration rather than shares; and (iv) the absence of any anticompetitive presumptions, in contrast to the HMGs.

The discussion of the safe harbor in the dVMGs is quite brief. But the safe harbor and its flaws raise some complex issues. Therefore, to frame our analysis, it is useful to summarize our concerns at the outset.

First, we do not think that a safe harbor is desirable. As will be discussed below in detail, it is difficult to specify a safe harbor based on rigorous economic analysis that will not lead to worrisome false negatives. In addition, we are concerned that adopting a safe harbor will lead

\footnotetext{
${ }^{8}$ As we discuss in Section III.A infra, in the context of the examples we present there, it also is not clear that the "share of output" by the related product is the appropriate measure for analyzing competitive issues or that it would properly capture the market share if a market were defined.
} 
the parties and the agencies to overly-focus on satisfying the safe harbor rather than on analyzing the potential competitive concerns raised by the merger. Particularly now, when the agencies are stressing the need to employ a modern economic approach to analyzing vertical mergers, maintaining a single-minded focus on the competitive effects has substantial benefits for the enforcement system.

Second the use of the shares of the merging firms is a flawed metric for any safe harbor. Foreclosure can be profitable and lead to substantial competitive harms even if the shares are less than $20 \%$. In the case, of input foreclosure, for example, the key issue for the downstream firm is whether it will attract significant diversion, which can occur even if it has a low pre-merger share. The key issue for the upstream firm is whether its input price will lead to the foreclosed downstream rivals suffering material cost increases that would lead to that significant diversion, which also can occur even if the upstream firm has a share of less than $20 \%$. Coordination also could be facilitated if the merging firm has a share of less than $20 \%$ in one of the markets, for example, if one of the merging firms is a maverick or disruptive input purchaser.

Third, if a safe harbor is considered essential, it should be based on measures of concentration in both upstream and downstream relevant markets, not based the shares of the merging firm. Both relevant markets would need to be defined because the safe harbor would apply to concerns about competitive harm in either market. To diminish the potential for under-deterrence, any such safe harbor should be very limited. If the agencies adopt a safe harbor based on concentration, we would recommend that it require that both markets be unconcentrated (i.e., $\mathrm{HHI}<1500$ ). We would also recommend that the VMGs explain that the two market definitions must be sensitive to switching costs and product differentiation that may limit input substitution, and that they may involve narrow price discrimination markets where the SSNIP is not uniform. The market definitions also may have to account for pre-merger vertical integration.

Fourth, as discussed in Section III.D, we recommend that certain anticompetitive presumptions also be adopted. Doing so will improve the error-cost tradeoff embodied in the VMGs by enhancing deterrence of anticompetitive mergers, which is particularly important on overall error-cost grounds if a safe harbor is adopted that insulates some mergers from enforcement. These anticompetitive presumptions would not necessarily be based solely on numerical values

(e.g., specific market shares or concentration levels); they could be based in addition or instead on more detailed market conditions.

As background, we begin why explaining why the use of "share of output" is generally an inappropriate basis for identifying or screening for competitive concerns.

\section{A. The Related Product's Low Share of Output Poorly Measures Lack of Competitive Concerns}

Instead of requiring the definition of a related market, the dVMGs merely identify a "related product" and then measure "the share of the output in a relevant market that uses the related 
products." The dVMGs use the "share of output" as a safe harbor. This measure is not well defined and its use will lead to several significant problems.

The dVMGs do not explain how input substitution should be incorporated into the analysis. In particular, the dVMGs do not explain what inputs are included in the "related product" category and which are not, in situations where there is actual or potential input substitution. (In fact, the dVMGs do not explicitly discuss the significance of input substitution anywhere, though it is relevant to understanding the likelihood that input prices would be affected by a vertical merger.)

The agencies do not explain how output is measured. We would expect the agencies to use a share of output measure that best captures the foreclosure threat, in order to tie the measure to the competitive effects concerns set forth later. For example, it is not made clear whether the agencies will measure the "units" in the numerator and denominator in terms of volume or revenue, which could make a substantial difference if inputs or outputs are differentiated. If the definition of the "related product" is intended to be the equivalent of "market definition" but without the label, then the "share of output" would be the equivalent of market share. In the HMGs, market share is normally (but not always) measured as a share of revenue. The term "share" also can take on different meanings and should be clarified. ${ }^{9}$

While Example 2 in the dVMGs applies to an input foreclosure concern, a safe harbor would apply to all competitive concerns. But it is not clear how the agencies would measure the share of the related product in the case of customer foreclosure, where the related product is the downstream product. It would appear that the analogous share would be the share of the sales of all the upstream firms that are purchased collectively by all the downstream firms. For example, if an input is used only by the downstream merging firm and its rivals, the analogous "share of output" would seem to be $100 \%$. The agencies should clarify how they would measure share of output in this setting.

Finally, returning to the example of input foreclosure concerns, we are particularly concerned that measuring the competitive significance of the upstream merging firm's related product by the "share of output" of all the downstream firms may be seen as equivalent to assuming an overly broad input market, even when a narrower market would be defined for analyzing a horizontal merger between input producers and when that narrower market (or a narrower related product segment) would be more appropriate for analyzing the input foreclosure concern. For example, suppose that the relevant market for analyzing an input foreclosure concern is the downstream market. According to the dVMGs, the "related product" would be the input manufactured by the upstream merging firm and its "share of output" would be the percentage of

\footnotetext{
${ }^{9}$ For example, in the case of the AT\&T/Time Warner merger, the Time Warner content was purchased by all (or virtually all) of the distributors, but its share of viewership was far less than $100 \%$. This raises the question of whether its relevant "share of output" would be $100 \%$ or whether it would be the share of viewership.
} 
output (presumably measured as volume or revenue) in the downstream relevant market that uses this input.

To illustrate a substantial problem with this approach of relying on the "share of output" that is related to the analysis of input substitution, consider first the following fact pattern of a horizontal merger of upstream suppliers.

Example A: Suppose that there are 5 downstream chemical producers, each producing approximately the same output level of a differentiated product and selling their products at the same price, and so that each has market share of about $20 \%$. Suppose that production requires the use of a catalyst as a critical input. Suppose that there are two catalyst types, $A$ and $B$, and two firms produce Catalyst A and three firms produce Catalyst B. Suppose that each producer of Catalyst A serves share of total downstream output equal to $20 \%$. But assume further that two of the downstream firms use only Catalyst A and cannot substitute to Catalyst B because of high switching costs. Suppose there is a horizontal merger of the two producers of Catalyst A.

On these facts, the HMGs might well define a narrow market limited to Catalyst A because of the lock-in from the two downstream firms' switching costs, even if the downstream market included the products of all 5 firms. By contrast, the "share of total downstream output" by each upstream firm is $20 \%$. This is equivalent to assuming that Catalyst $\mathrm{A}$ and Catalyst $\mathrm{B}$ are in the same market, making it less apparent that the merger can harm competition. ${ }^{10}$ This problem is inherent in the "share of output" concept used in the dVMGs.

Example A illustrates why an input's "share of total downstream output" is not a good basis for framing a safe harbor in a horizontal merger analysis. As will be seen in the examples in the next section, the same problem often may arise in vertical mergers.

The examples will show why using the share of output measure may lead to substantial underenforcement. If a share of output measure is to be used, it would be more appropriate to measure the share of output of the related product by particular individual downstream firms. In this way, the share of output concept might account for switching costs, product differentiation and other impediments to switching. As a starting point, even if a market is not formally defined, it would be necessary to evaluate the evidence to determine whether or not there would

\footnotetext{
${ }^{10} \mathrm{We}$ have constructed this example in a very stylized way in order to demonstrate the point in a simple context. The high switching costs imply that these two downstream firms are locked-in to Catalyst A. This might imply a price discrimination input market limited to Catalyst A. Even if there is downstream competition, it may be profit-maximizing for the merged firm to raise prices to the two Catalyst A users. For example, suppose that the products are differentiated and the products of the two firms locked-in to Catalyst A are relatively close substitutes, but a broader downstream market is defined; or suppose that the downstream product is homogeneous but the firms using Catalyst B have rising marginal costs that would limit expansion if the competitors using Catalyst A raised their prices.
} 
be a related product segment that is analogous to a price discrimination market for the supply of the input and consider an analogous share measure there, even though a relevant input supply market does not have to be defined as a matter of law when litigating vertical merger cases. This complexity also counsels against using the share of output concept for defining a safe harbor.

\section{B. The 20-20 Share-Based Safe Harbor Screen is a Defective Measure of Unlikely Competitive Harms}

Building on the above analysis, we have serious concerns about the 20-20 safe harbor screen in the dVMGs and recommend that it be deleted. ${ }^{11}$ There is no rigorous economic basis for focusing solely on shares, and the dMVGs do not offer any rationale. Nor do the dVMGs provide a rationale for the $20 \%$ thresholds. Our economic analysis (as illustrated by the examples below) show why the safe harbor is inadequate.

We are concerned that this proposed safe harbor is overly permissive and will lead to substantial under-enforcement, even in settings besides the one noted in the dMVGs (i.e., when the related product is new and its share of use in the relevant market is growing). Not only would the safe harbor exempt worrisome transactions, but it would also implicitly raise the enforcement bar for transactions that are arguably "close to" the safe harbor levels. ${ }^{12}$

The following hypothetical economic examples illustrate how the dVMGs' share-based safe harbor does not accurately screen out anticompetitive conduct. The first three examples involve input foreclosure. In the fourth example, the harm comes from anticompetitive coordination. In the fifth example, the harm comes from customer foreclosure. The mergers in the examples would not necessarily be found to harm competition after a full analysis. But in plausible situations they would be, yet that possibility would escape any analysis through application of the safe harbor.

We begin with a vertical merger based on the facts of Example A. Our example illustrates the problem created when the share of output is measured as if there were a possibly overbroad market when analyzing the competitive effects of a vertical merger. It also illustrates how the market share in the downstream market can understate the competitive concerns from merger.

\footnotetext{
${ }^{11}$ We recognize that it is not technically a complete safety zone - that there is a difference between "unlikely" to challenge and an absolute "will not" challenge, and that the dMVGs disclaim treating the share thresholds as a "rigid screen." But we would expect it to operate in practice as a safe harbor, much the HMGs treat mergers satisfying the lower HHI screens, despite the qualifying language that such mergers "ordinarily" require no further analysis. See HMGs at 19.

${ }^{12}$ For example, the agencies are much less likely to bring enforcement actions when horizontal mergers have HHIs below the "highly concentrated" threshold, even though that is not a safe harbor threshold in the HMGs. See John E. Kwoka, Reviving Merger Control: A Comprehensive Plan for Reforming Policy and Practice $\S 4.1$ (October 9, 2018), https://www.antitrustinstitute.org/work-product/aai-advisor-johnkwoka-lays-out-new-merger-control-policy-calls-for-key-reforms/.
} 
Example B: Using the same basic market facts as Example A, suppose instead that there is a vertical merger between one of the two downstream firms locked-in to Catalyst A and one of the two producers of Catalyst A, each of which has a market share of $20 \%$ (or slightly less if we change the shares trivially). That vertical merger could provide an incentive for the upstream merging partner to engage in input foreclosure by substantially raising the price it charges the other locked-in Catalyst A user, anticipating that this would provide an incentive for the other Catalyst A supplier to respond in an accommodative way by raising its own price to the other user of Catalyst A. Even if the foreclosed downstream merging firm has a market share of only $20 \%$, it might gain enough diversion to make a raising rivals' cost or total foreclosure strategy profitable.

This example shows that the focus on the market share in the relevant market and share of output in the related market in the 20-20 safe harbor can hide a significant input foreclosure concern. A vertical merger can have substantial anticompetitive effects from input foreclosure even if the share of the merging firm in the downstream market is low. The share of output measure in the dVMGs may mislead because it implicitly assumes that the input market is broader than may be appropriate. The downstream firm's market share is a flawed metric because the profitability and competitive harm arises from diversion from the rivals of the merging firm whose costs are raised from input price increases or foreclosure. Even if the share of the downstream merging firm is less than $20 \%$, its share could grow substantially enough from that diversion to make the foreclosure profitable.

We next create a variant of the dVMGs' Example 3 (i.e., a vertical merger between an upstream orange producer and a downstream orange juice competitor) in which there are switching costs but not total lock-in. The competitive concern is that after the merger, the orange grove would foreclose access to its oranges to the competitors of its downstream orange juice merger partner, either through total foreclosure or with input price increases. In this example, the 20-20 safe harbor generates a false negative because it fails to account for concentration in the relevant product (here, the downstream product).

Example C: Suppose that oranges are differentiated by size. Assume that there is some input substitution among sizes by the juice makers, but that the equipment of each juice producer is optimized for a particular size, such that its production costs would be significantly higher if it uses other sizes. Suppose that there are 3 orange juice producers. Suppose that the two smaller firms, with shares of $16.7 \%$ each, are optimized to use the same sized oranges. The third juice producer, with a share of $67 \%$, owns multiple equipment types and uses all sizes. In addition, suppose that the $67 \%$ firm already is partially integrated and owns some orange groves itself. 
Given these market conditions, suppose that one of the two smaller orange juice producers acquires an unintegrated orange grove that supplies some of its optimally-sized oranges. Suppose further that the acquired orange grove accounts for less than $20 \%$ of the total oranges used by all three of the juice producers. The merger would fall within the 20-20 safe harbor.

A potential competitive effects concern here is that the merged firm would materially raise its price of oranges or refuse to sell any of the acquired grove's oranges to the other juice producer that also prefers the same size oranges. If it does, suppose it significantly raises the costs of the targeted juice; or suppose that the targeted juice producer is unable buy sufficient oranges from the other groves at a price that allows it to be viable and exits as a result. Suppose further that its customers divert proportionally to the remaining two juice firms. This vertical merger thus could lead to a reduction of the number of juice firms from 3 to 2 , and create a downstream duopoly that likely would raise downstream prices. Yet, this transaction would be immunized from analysis by the safe harbor.

The results of this example do not turn on the possibility that the downstream rival is completely foreclosed and must exit, rather than simply having its costs substantially increased. Instead, the safe harbor leads to under-enforcement because it uses the problematic "share of output" concept when there is product differentiation upstream and because it ignores the level of concentration in the downstream market. It similarly ignores the level of concentration in the upstream supply. ${ }^{13}$

The next example illustrates how the 20-20 safe harbor can generate a false negative because it does not account for upstream concentration in the sale of the related product, even when the upstream merging firm has a share of only $20 \%$.

Example D: Consider the acquisition by an automobile original equipment manufacturer ("OEM") of one of the only two manufacturers of mechanisms to control convertible tops. Assume further that the two competing mechanisms are very close substitutes, which leads to pre-merger prices that are very close to marginal cost. The competitive effects problem involves input foreclosure, with convertible automobiles as the relevant downstream market and mechanisms as the upstream related product.

\footnotetext{
${ }^{13}$ This example also illustrates a general point that we discussed in the Overview section. By providing inputs to the rivals of the future downstream merging firm in the pre-merger market in competition with other upstream firms, the upstream merging firm supports competition in the downstream market. After the merger, the upstream merging firm may have the incentive to reduce or withdraw this support. In this sense, the upstream merging firm has some indirect control over the costs of the downstream rivals and their ability to compete with the downstream merging firm.
} 
Suppose that the merging mechanism manufacturer has a share of (just under) $20 \%$, while the other mechanism manufacturer has a share of (just over) $80 \%$. Suppose the acquiring automobile OEM has share of convertibles of (just under) $20 \%$, and that convertibles are a relevant output market. This vertical merger would fall within the 20-20 safe harbor.

If the merged firm raises the price of its mechanisms to other convertible automobile manufacturers, the competing mechanism firm would gain the power to raise its mechanism prices to the other convertible OEMs. As a result, there would be diversion to the downstream merging firm and convertible prices likely would rise. ${ }^{14}$ The 20-20 safe harbor entirely misses the competitive problem here because it does not account for concentration in the supply of the related product. Note that the harm from this input foreclosure does not require the downstream merging firm to have a high share or for there to be high concentration in the convertible automobile market. ${ }^{15}$

The safe harbor examples in the dVMGs concern input foreclosure. But the same safe harbor conditions apply to all competitive problems. This next example illustrates how the 20-20 safe harbor can overlook significant coordinated effects concerns.

Example E: Consider the acquisition by an automobile OEM of a steel company that has a steel market share of (just under) 20\%. Suppose there are five almost equally-sized automobile manufacturers, each with a downstream market share of around $20 \%$ and the OEM merger partner's share is just under $20 \%$, so the merger falls within the 20-20 safe harbor. Suppose that the merging steel company's major customer is a maverick OEM that has been responsible for disrupting or limiting coordination among the OEMs. As noted in Section 7 of dVMGs, foreclosing this maverick could facilitate coordination in the downstream automobile OEM market or make it more effective and thereby lead to market power which harms automobile consumers, if the maverick OEM cannot switch its input purchases to other steel companies without suffering a

\footnotetext{
${ }^{14}$ In this sense, the merger and the input foreclosure also facilitate coordination in the upstream market, where mechanisms could be seen as the relevant product. The dVMGs do not discuss this possible complication as a separate competitive problem when the primary issue is unilateral input foreclosure.

${ }^{15}$ As the example illustrates, if the input supply (or input market) is concentrated, for example, as result of price discrimination narrowing the market, then profitable input foreclosure does not require that the downstream market also be concentrated. This is because input foreclosure that materially raises the cost of all or most of the competitors in an unconcentrated downstream market could cause substantial diversion to the merged firm's downstream affiliate and permit it profitably to gain power to raise or maintain supracompetitive prices.
} 
cost penalty. ${ }^{16}$ But the 20-20 safe harbor generates a false negative because it does not account for the role of the maverick in constraining coordination in the automobile market. The likelihood of a false negative (including underdeterrence) would be reduced (but not eliminated) if the safe harbor were applied only when the relevant market is unconcentrated, as is done by the HMGs. ${ }^{17}$ This change would not create false positives because the merger would still be subject to a full analysis.

This next example illustrates how the 20-20 safe harbor can overlook a customer foreclosure concern, depending on how the "share of output" concept is measured, when the relevant market is the upstream input and the related product is the downstream product.

Example F: The production technology of two OEMs (denoted as OEMs $A$ and $B$ ) requires the use of a specialized steel alloy manufactured only by two steel makers (denoted as $S 1$ and $S 2$ ), each of which has a similar technology. The alloy products of these suppliers are close substitutes for OEMs $A$ and $B$, and thus compete intensely so that their alloy prices are very close to marginal cost. Suppose that OEMs $A$ and $B$ each account for $20 \%$ of automobile sales. Each buys half of its specialized steel from supplier $S 1$, and half from supplier $S 2$. The other automobile OEMs do not and cannot use this specialized steel, so suppliers $S 1$ and $S 2$ each account for $20 \%$ of automobile output. Suppose automobile OEM $A$ acquires supplier $S 1$ and expands output to totally selfsupply. Losing half of its sales, supplier $S 2$ exits the sale of this auto specialized steel market. As a result, the acquired steel producer raises the prices it charges OEM $B$, which is harmed.

In this example, the best relevant market for evaluating the competitive harm is the sale of the specialized steel alloy to OEM $B$. If this were recognized by the agencies, the safe harbor would not apply. But it would not be surprising if, during an initial investigation, the agency mistakenly thought that the safe harbor was satisfied, simply because that OEM $A$ and steel producer $S 1$ each account for only $20 \%$ of sales in their respective levels, without recognizing that this approach misleads.

\footnotetext{
${ }^{16}$ In the setting of the example, a similar false negative could occur if the upstream merging firm is a maverick steel producer or the downstream merging firm is a disruptive steel purchaser that prevent upstream coordination. The 20-20 safe harbor similarly would overlook the possibility that the vertical merger would change the incentives of the merging firms, and thereby lead to coordination among the steel manufacturers.

${ }^{17}$ Even in unconcentrated downstream markets, the merger could harm competition if the merged firm correctly expects accommodating responses by non-merging firms.
} 
These examples demonstrate that a safe harbor based on shares systematically overlooks valid concerns about competitive harms, and thus why economic theory would not provide the foundation for the safe harbor proposed in the dVMGs. In the examples, shares are not good proxies for the likelihood of competitive harm because they ignore the shares of other firms and their possible accommodative responses, a key element of the economic analysis of competitive effects. ${ }^{18}$ They also overlook the potentially disproportionate competitive role of small competitors as mavericks or disruptive competitors.

\section{Is a Safe Harbor Even Needed and If So, How Should It Be Structured?}

We recommend that a safe harbor not be adopted. In light of the various ways in which vertical mergers can harm competition, as illustrated by the above examples, any safe harbor inevitably will exempt worrisome transactions from analysis. A safe harbor also would have the effect of raising the enforcement bar for transactions that are arguably "close to" the safe harbor levels. ${ }^{19}$ If, notwithstanding our recommendation, the final VMGs do incorporate a safe harbor, it should instead be based on a showing of that both the upstream and downstream relevant markets are unconcentrated. Both markets would need to be defined because the safe harbor would apply to customer foreclosure as well as input foreclosure, as well as coordination in either the upstream or downstream market. ${ }^{20}$ If both markets are defined for the purpose of applying a safe harbor, it will be hard to avoid doing so for the purpose of analyzing competitive effects (notwithstanding the way the dVMGs specify a related product but not a related product market). Moreover, as the examples above demonstrate, if even one of the levels is unconcentrated, there could still be a significant risk of competitive harm.

As the examples illustrate, the definition of the relevant market for what the dVMGs term the related product must be sensitive to switching costs, product differentiation and other impediments that limit or eliminate input substitution for some or all input purchasers. The presence of such impediments to input substitution may suggest that there are narrow price discrimination markets where the relevant SSNIP is not a uniform price increase. If there is premerger vertical integration, it also may be necessary to account for any pre-merger raising rivals' costs or EDM by the integrated firms, as suggested in footnote 4 of the HMGs. Thus, application of such a safe harbor also may not be easy.

\footnotetext{
${ }^{18}$ Some commentators might classify this accommodative response as a type of coordinated effect rather than as a unilateral effect. Whichever way it is classified, its competitive impact is the same.

${ }^{19}$ As noted earlier, supra note 12 , the agencies are much less likely to bring enforcement actions when horizontal mergers have HHIs close to the safe harbor thresholds.

${ }^{20}$ The possibility that competitive harm could arise at either vertical level also means that both markets need to be defined to apply the 20-20 safe harbor.
} 
All in all, these complications counsel for using concentration as potentially probative evidence in a full competitive effects analysis rather than adopt a safe harbor based either on concentration or shares.

However, if the agencies conclude that incorporating a safe harbor is essential, then basing a safe harbor on both relevant markets being unconcentrated is a better approach than the share-based safe harbor because it reduces the risk of under-enforcement. If such a safe harbor is adopted and this approach is employed, we suggest that the agencies define "unconcentrated" using the same $1500 \mathrm{HHI}$ threshold employed by the HMGs. ${ }^{21}$ We agree that vertical mergers raise greater concerns in more highly concentrated oligopoly markets. But since classifying a merger within a safe harbor precludes further analysis, the concern of avoiding under-enforcement would counsel for a low concentration threshold. ${ }^{22}$

A Qualcomm counsel, Koren Wong-Ervin, ${ }^{23}$ suggests that the safe harbor should be even more permissive because, she says, vertical mergers are often procompetitive. ${ }^{24}$ For example, WongErvin proposes a 30\% market safe harbor threshold instead of $20 \%$. While we expect that benign vertical mergers will occur more often in unconcentrated markets, the empirical relationship between concentration and proposed mergers is generated by the shadow of the law. Benign mergers may be more often proposed because they are quickly approved.

\footnotetext{
${ }^{21}$ We noted a concentration-based safe harbor in our Five Principles article without suggesting an HHI level. We also suggested that the HHI be measured in two separate ways. See Baker et al., supra note 2, at $15 \&$ n.53.

${ }^{22}$ Moreover, the fact that vertical mergers in markets with 2500 HHIs might on average be more concerning than those in markets with 1500-2500 HHIs does not mean that all vertical mergers in markets with 1500-2500 HHIs should be exempt from analysis. Horizontal mergers also are assumed more likely to be anticompetitive as concentration grows, but the primary safe harbor for horizontal mergers is 1500 , not 2500 .

${ }^{23}$ Koren Wong-Ervin, U.S. Vertical Merger Guidelines: Recommendations and Thoughts on EDM and Merger Specificity, COMPETITION POLICY INT'L (January 22, 2020), https://www.competitionpolicyinternational.com/u-s-vertical-merger-guidelines-recommendations-andthoughts-on-edm-and-merger-specificity/.

${ }^{24}$ In fact, Wong-Ervin suggests that vertical mergers should be entitled to a procompetitive presumption, even in highly concentrated oligopoly markets, based on her claim that this presumption is supported by empirical studies. $I d$. We have explained elsewhere why a procompetitive presumption is not in fact supported by the economics literature, and we commend the agencies for declining to adopt it. See Baker et al., supra note 2, at 14; Salop, supra note 2, at 1969-70. Wong-Ervin fails to recognize the shortcomings of many of the empirical studies that she references. See Wong-Ervin, supra note 23. Evaluation of the more recent empirical studies and discussion of the substantial limitations of earlier empirical studies can be found in Marissa Beck \& Fiona Scott Morton, Evaluating the Empirical Evidence of Competitive Effects from Vertical Mergers (February _, 2020) (forthcoming) that is also submitted as a Comment in these proceedings.
} 
Finally, we are concerned that adopting a safe harbor will lead the parties and the agencies to overly-focus on satisfying the safe harbor rather than on analyzing the potential competitive concerns raised by the merger. Particularly now, when the agencies are stressing the need to employ a modern economic approach to analyzing vertical mergers, maintaining a single-minded focus on the competitive effects has substantial benefits for the enforcement system.

\section{Anticompetitive Presumptions Should be Adopted}

The HMGs contain an anticompetitive presumption as well as safe harbors. Despite adopting a safe harbor, the dVMGs do not suggest applying any anticompetitive presumptions to the most worrisome market structures. This asymmetric approach raises concerns that the final VMGs could be biased toward under-enforcement, since policy concerns involving both over- and under-enforcement must be considered when striking a sensible error cost balance. In addition, recent evidence suggests that under-enforcement has been especially costly for consumers. ${ }^{25}$ The lack of any anticompetitive presumptions also is surprising in that the Clayton Act is an "incipiency" statute, and thus places more weight on avoiding false negatives than does the Sherman Act. ${ }^{26}$ Anticompetitive presumptions would be valuable additions to the VMGs regardless of whether safe harbors are included.

Anticompetitive presumptions do not need to be based solely or even primarily on specific numerical metrics. Anticompetitive presumptions can sensibly be based on various market conditions, as we suggest in our Five Principles article. ${ }^{27}$ Following an approach similar to that employed in the HMGs, the final VMGs might implement such presumptions by stating that when the triggering conditions are met, the merger will be presumed likely to maintain or enhance market power. They may add that the presumption may be rebutted by persuasive evidence.

One particularly important anticompetitive presumption would apply to vertical mergers involving dominant platforms that are protected by network and scale economy barriers to competition. Our article proposes an anticompetitive presumption for such mergers. ${ }^{28}$ When a dominant firm acquires a vertically-related firm that is a potential or nascent competitor, or one that could facilitate the entry and growth of a fringe rival or potential rival, it could prevent the

\footnotetext{
${ }^{25}$ Jonathan B. BAKer, The Antitrust PARAdigm 11-31 (2019); Jonathan B. Baker \& Fiona Scott Morton, Confronting Rising Market Power 1 (Econ. For Inclusive Prosperity, Research Brief May, 2018), https://econfip.org/wp-content/uploads/2019/05/Confronting-Rising-Market-Power.pdf; Fiona Scott Morton, Modern U.S. Antitrust Theory and Evidence Amid Rising Concerns of Market Power and Its Effects: An Overview of Recent Academic Literature, WASH. CTR. OF ECON. GROWTH (May, 2019), https://equitablegrowth.org/wp-content/uploads/2019/05/052819-antitrust-lit-rev.pdf.

${ }^{26}$ As explained by the DC Circuit in United States v. AT\&T, "Section 7 'applies a much more stringent test than does the rule-of-reason analysis under Section 1 of the Sherman Act." 916 F.3d 1029, 1032 (quoting Brown Shoe Co. v. United States, 370 U.S. 294, 318 n.33 (1962)).

${ }^{27}$ Baker et al., supra note 2, at 16-17.

${ }^{28} \mathrm{Id}$.
} 
disruption of its dominance and the substantial competitive and consumer benefits that would follow.

The presumption of competitive harm from vertical mergers involving dominant platforms would apply when a dominant platform acquires a competitor in an adjacent market, or when it acquires a vertically-related firm (or, we would add, a firm selling a complementary product) that would support competition with the platform or that has a reasonable probability of entering in competition with the platform absent the merger. As previously indicated, we think the final VMGs should apply to mergers between sellers of complements, not just to mergers between vertically-related firms, so the presumption would often apply when a dominant platform company acquires a firm participating in an adjacent market.

As we explain in our article, this presumption is important because firms participating in vertically-adjacent or complementary markets are often potential entrants, so the presumption would reach nascent threats to dominance created by potential entrants that would be eliminated by the acquisition. The presumption also recognizes that a dominant platform's market power would give it the ability to substantially disadvantage firms in adjacent markets by choosing not to interoperate, which also is a foreclosure concern. ${ }^{29}$ By adopting this reasoning, the Agencies could address the rising concern that current enforcement practices contain a significant gap with respect to the acquisition of nascent and potential competitors.

Competitive harms from the elimination of a potential entrant through acquisition by a dominant platform or by any other vertically-related firm in principle also may be covered by the HMGs. Section 5.1 of the HMGs treat "rapid entrants" as market participants and Section 5.3 indicates that they may be assigned a projected market share. However, we are concerned that the HMGs do not adequately capture all the relevant competitive concerns. ${ }^{30}$ The HMGs' approach is mainly focused on potential entrants that will rapidly and almost surely compete with current products. By contrast, vertical (or complementary product) mergers by dominant platforms in industries where the technological frontier is moving out rapidly often involve acquisitions of firms that would compete in future products and only become substitutes in the future, or, similarly, compete in innovation to develop new or improved products. Those mergers may harm competition even if they are not easily characterized as acquisitions of rapid entrants, so it is helpful and appropriate to discuss them in the final VMGs. Economists who study antitrust

\footnotetext{
${ }^{29}$ This presumption can be understood as an application of two other presumptions we proposed in our article - the elimination of potential entry presumption and an input or customer foreclosure presumption - in a setting where network effects and economies of scale would be expected to raise barriers to entry, and thus endow a dominant platform with substantial market power.

${ }^{30}$ We note that potential entry mergers were treated as "non-horizontal" in the 1984 Non-Horizontal Merger Guidelines, which means that they were not fully captured by the HMGs. U.S. DEP'T OF JUSTICE, NON-HORIZONTAL MERGER GUIDELINES (1984), https://www.justice.gov/sites/default/files/atr/legacy/2006/05/18/2614.pdf.
} 
issues increasingly recognize that these potential entrants play an important role in maintaining competition and need protection.

Our earlier article also proposes presumptions of competitive harm arising from several other possible sources to be applied, but only when certain market conditions are met. ${ }^{31}$ These would be applicable for input and customer foreclosure, the elimination of a potential entrant; the acquisition of a maverick or disruptive seller; or evasion of regulation. The triggering market conditions differ for these various presumptions.

\section{Section 4: Evidence of Adverse Competitive Effects}

Our main comment here is that the VMGs (or an associated Commentary issued simultaneously) would benefit greatly by including a more detailed listing of the types of evidence that are relevant in evaluating the various competitive harms concerns. Because these revised VMGs are new and recent agency precedents are sparse, firms and the antitrust practitioners who counsel them would benefit from more information than is contained in the HMGs. We make some specific suggestions in these comments. ${ }^{32}$

The final VMGs also would benefit from discussing the various dimensions along which vertical mergers can harm competition. ${ }^{33}$ The dVMGs focus on price increases and associated reductions in output. But anticompetitive vertical mergers also can lead to lower quality products, or reduced or delayed innovation. These anticompetitive effects could be immediate or might develop over a longer time frame.

We also note that while the dVMGs connect themselves to the HMGs, here and elsewhere, they do not explain how the agencies will analyze mergers that are both vertical and horizontal. Nor do they discuss the important connections between vertical and horizontal merger theories. It would be useful to do both in the final VMGs, either in a new section or as part of the analysis of unilateral and coordinated effects.

It would be useful to identify ways that vertical integration can increase the likelihood of anticompetitive effects of horizontal mergers. For example, when firms are vertically integrated,

\footnotetext{
${ }^{31}$ Baker et al., supra note 2, at 16-17.

${ }^{32}$ For other examples of the types of evidence that might be referenced, see Steven C. Salop \& Daniel P. Culley, Revising the U.S. Vertical Merger Guidelines: Policy Issues and an Interim Guide for Practitioners, 4 J. ANTITRUST ENFORCEMENT 1 (2016).

${ }^{33}$ In addition to the possibilities discussed in the text, vertical mergers can lead to the exercise of buyerside market (monopsony) power. That could occur, for example, if the upstream merging firm is a disruptive competitor on the buy-side, preventing the upstream firms from coordinating to depress input prices (or wages) paid to their suppliers further upstream. It could also occur if the downstream merging firm is a disruptive buy-side competitor, preventing the downstream firms from coordinating to depress input prices from the upstream firms. If the merged firm has a different incentive, the acquisition could harm competition on the buy-side.
} 
a horizontal merger at either level could raise input foreclosure or customer foreclosure concerns that could exacerbate upward pricing pressure (unilateral effects) of the horizontal merger. This scenario might occur, for example, in a transaction combining two platforms. ${ }^{34}$ In addition, vertical integration can increase the likelihood of anticompetitive coordinated conduct arising from a horizontal merger. These issues are illustrated by the recent successful private case brought by Steves \& Sons challenging the 2012 Jeld-Wen/CMC merger. ${ }^{35}$

The new section could also observe that a horizontal acquisition involving an integrated firm could lead to competitive benefits, either EDM or efficiencies of vertical coordination. It is appropriate to discuss these possibilities in the final VMGs because some acquisitions have both vertical and horizontal aspects.

\section{Section 5: Unilateral Effects}

Our comments on this section focus on four recommendations regarding discussion of unilateral effects in the dVMGs: (i) clarifying the analysis of foreclosure and raising rivals' costs, (ii) including competitive concerns currently omitted from the section; (iii) eliminating the reference to pre-merger profitability in the profitability test; and (iv) eliminating quantification requirements. We are concerned that the current approach taken in the dVMGs will lead to under-enforcement and false negatives. Our suggested approach can reduce the likelihood of false negatives without leading to more false positives.

\section{A. The Analysis of Foreclosure and Raising Rivals' Costs Should be Clarified}

In our view, the dVMGs would be improved by clarifying their analysis of foreclosure and raising rivals' costs (Section 5a). The dVMGs appear to recognize that these effects include both input foreclosure and customer foreclosure, though the examples focus almost exclusively on input foreclosure. ${ }^{36}$ They could usefully say so explicitly. The language of the dVMGs

\footnotetext{
${ }^{34}$ Merger-specific EDM likely would be small or non-existent in such a transaction.

${ }^{35}$ Steves \& Sons, Inc. v. JELD-WEN, Inc., No. 3:16-CV-545 (E.D. Va. Dec. 14, 2018). Jeld-Wen and Masonite were vertically integrated firms that sold interior molded doors. A key input for those doors is doorskins. Both firms competed to sell doorskins to unintegrated door manufacturers, including Steves. In 2012, Jeld-Wen acquired CMC, which was a major supplier of doorskins to unintegrated door producers. Two years after the merger was cleared by the DOJ, Masonite announced that it would no longer compete for such sales. This led Jeld-Wen to raise its doorskin prices and announce that it was terminating its contract with Steves when it expired. Both firms also raised door prices. DOJ did not issue a complaint. But Steves brought a successful antitrust action, which it won in 2018. For further details, see Steven C. Salop, Analyzing Vertical Mergers to Avoid False Negatives: Three Recent Case Studies, 33 ANTITRUST 27 (2019).

${ }^{36}$ The foreclosure examples in the dVMGs include unilateral total foreclosure (Examples $3 \& 5$ ) and price increases resulting from bargaining (Example 4). The inputs could be withheld from existing firms (Example 3) or potential entrants (Example 5). Example 6 could be understood as an example of input
} 
distinguishes between "foreclosure" (i.e., total withholding of supply as in Example 3) and "raising rivals' costs" (as by raising prices). We suggest a minor change in language that would use the term "foreclosure" (or "RRC foreclosure") to refer to all the ways that rivals can be disadvantaged. ${ }^{37}$ In this case, the term "total foreclosure," "complete foreclosure," or "total withholding" would be used to refer to the conduct in Example 3. It also would be useful to note that the exclusionary conduct also could involve degradation of quality or service, or delays in access to new products or interoperability.

The dVMGs recognize that in quantitative modeling of unilateral price effects from merger arising from foreclosure or raising rivals' costs, it is often important to include "independent price responses by non-merging firms." The final VMGs should indicate that this possibility is relevant to evaluating unilateral effects, regardless of whether or not the agency quantitatively models those effects. These potential effects may be overlooked or misunderstood and so would benefit from further explanation. For these reasons, the final VMGs should spell out the significance of responses by non-merging firms more fully. We suggest, at a minimum, adding a sentence like this to the first paragraph of Section 5a in the discussion of input foreclosure: "The response of non-merging upstream firms supplying the related product also can strengthen the incentive of the merged firm to foreclose or raise rivals' costs by making accommodating price increases, particularly when the non-merging input suppliers have differentiated products or rising marginal costs, or where the supply of the input is concentrated." 38

We are also concerned that the dVMGs' failure to provide more detail about customer foreclosure - and the interaction between customer and input foreclosure-will lead to confusion or an enforcement gap. We recommend that the final VMGs add more detail on this issue.

For example, suppose that after acquiring an input supplier, a significant downstream firm stops purchasing from a targeted upstream competitor (customer foreclosure). The loss of these sales could drive the targeted competitor to exit the market, substantially reduce its investment or innovation incentives, or suffer higher variable costs if its technology involves strong scale economies. These effects could provide the upstream merging firm with the power to raise its prices, either unilaterally or in coordination with other upstream firms. These price increases could involve sales to customers that compete with the downstream merging firm, that is, input foreclosure. The price increases also could involve sales to customers in a separate downstream

foreclosure where distributors are treated as supplying an input (distribution services) rather than as customers.

${ }^{37}$ The economic and antitrust policy literature, and some modern cases, use the term "foreclosure" for the general category. "RRC foreclosure" is the general term in Steven C. Salop, The Raising Rivals' Cost Foreclosure Paradigm, Conditional Pricing Practices, and the Flawed Incremental Price-Cost Test, 81 ANTITRUST L.J. 371, 376 (2017).

${ }^{38}$ The discussion might be accompanied by a footnote that explains that this effect may be mitigated if non-merging firms have both the ability and incentive to reposition their products to offer close substitutes at lower prices. See, e.g., the discussion at the end of Section 6.1 of the HMGs. 
market in which the downstream merging firm does not compete. Either way, the input foreclosure works in tandem with the customer foreclosure to generate competitive harm.

This analysis can be illustrated with the following example.

Example G: Suppose that airlines that serve a particular hub city purchase jet fuel from three local oil refineries. Suppose that the largest airline serving the hub acquires one of the refineries and stops purchasing from the other two refineries. Suppose that the loss of these sales causes the smaller of the two refineries to become markedly less efficient, leading it to stop producing any jet fuel. Finally, suppose that the two surviving jet fuel suppliers, facing less competition, raise the price of fuel to the other airlines that serve the hub, both on routes in which the acquiring airline competes and others that it does not serve. As a result, air fares on all routes to and from the hub may rise.

We similarly recommend that more attention be paid to explaining the way in which foreclosure threats play out in the bargaining analysis used in the dVMGs' Example 4. ${ }^{39}$ It is clear from AT\&T/Time Warner that this issue can be misunderstood and easily distorted. The discussion could explain that the fact that permanent "blackouts" rarely (if ever) occur is indeed predicted by economic theory because carrying out the threat is off the equilibrium path. Not seeing the threat being carried out very often is therefore completely consistent with bargaining theory. Bargaining theory is premised on blackout threats, not necessarily carrying out the threats with actual blackouts. For the same reason, there is no profit sacrifice by upstream division from these negotiation threats. The upstream division is able to negotiate a higher price after the merger as a result of its increased bargaining leverage. Profits would be sacrificed only if no agreement is reached or if an agreement is delayed. But, economic theory predicts that even short-term blackouts would be rare or limited because the parties have mutual incentives to avoid them by reaching a quick agreement. The discussion also could make it clear that foreclosure and foreclosure threats are made one day at a time, not permanently as one-time nuclear war, and that credibility is achieved simply by failing to agree one day at a time when the delay is sufficient to change the likely allocation of the gains from trade in a favorable direction. Stated

\footnotetext{
${ }^{39}$ The final VMGs would also benefit from spelling out the bargaining theory in more detail. To explain more fully what happens when a vertical merger increases bargaining leverage (supposing the relevant market is downstream and the related market upstream), they might say, for example: "In a bargaining setting, a vertical merger may raise rivals' costs by enhancing the ability of the upstream affiliate of the merged firm to negotiate a higher price. After the merger, the upstream affiliate and customers that are downstream rivals will recognize that the downstream affiliate will earn more if the upstream affiliate were to foreclose the downstream rivals from access to the input. That makes it less costly than before the merger for the upstream affiliate to fail to reach agreement. In consequence, the merger will increase the bargaining leverage of the upstream affiliate, providing it with the ability to negotiate higher prices, and thereby also harm downstream competition by raising rivals' costs."
} 
differently, even if the threat of a permanent or long-term blackout lacks credibility, threats to delay the agreement for one more period could readily be credible. ${ }^{40}$

Finally, we also encourage revision to the statement that the agencies will consider whether “[ $\mathrm{t}$ ]he magnitude of likely foreclosure or raising rivals' cost is not de minimis such that it would substantially lessen competition." We found this remark very unclear. One possible interpretation could be that it is intended to say that the Clayton Act would be violated even when the price increase (in a case where buyers are victims) may appear small in absolute or percentage terms, but where the aggregate transfer of wealth across all the victims of the exercise of market power is not trivial. We agree that it is worth protecting consumers from any aggregate harm above a de minimis level. Another possible interpretation could be that the remark is intended to say that if the cost increase suffered by the targeted downstream firm (in an input foreclosure case) is de minimis, then there is unlikely to be competitive harm in the downstream relevant market. For example, it is unlikely that a law firm will increase the prices it charges for legal services and lose business, if, as a result of foreclosure, it faces a $10 \%$ increase in the price it pays for paper clips.

We are concerned that this remark about de minimis effects could be misread as suggesting that the agencies, in their enforcement discretion, recognize a tolerance level for price increases (or other competitive harms) from merger - or worse, that the agencies interpret the Clayton Act to do so. We thus encourage clarification of the remark. We also encourage the agencies explicitly to disclaim that they recognize a tolerance level for competitive harm, consistent with the first interpretation. ${ }^{41}$ Moreover, a tolerance level would appear to call for quantification, which, as we discuss below, is neither required by the courts nor consistent with DOJ policy. ${ }^{42}$

\section{B. Currently Omitted Competitive Concerns Should be Included}

The dVMGs do not explicitly reference a number of potential competitive concerns, including ones that appear in the economics literature and antitrust analysis highlighted below. We hope

\footnotetext{
${ }^{40}$ See Thomas Schelling, The Strategy of Conflict 41-46 (1960). For an application to AT\&T/Time Warner, see Brief for 27 Antitrust Scholars as Amici Curiae in Support of Neither Party 1530, United States v. AT\&T, 916 F.3d 1029 (D.C. Cir. 2019) (No. 18-5214); Steven C. Salop, The AT\&T/Time Warner Merger: How Judge Leon Garbled Professor Nash, 6 J. ANTITRUST ENFORCEMENT 459, 463-64 (2018).

${ }^{41}$ See HMGs, supra note 3, at 9 (SSNIP is not a tolerance level for price increases resulting from a merger). A merger violates Section 7 of the Clayton Act if there is a reasonable probability that it would lead to an increase in price (or other harm to competition) of any magnitude, no matter how small. In practice, the enforcement agencies do not commonly challenge mergers when the adverse effect is thought to be very small - but not because the statute calls for a tolerance level. It may be difficult to prove a case when the competitive effect could be small when there are difficulties measuring effects with precision. Moreover, the enforcement agencies may prefer to not employ their resources to pursue violations with a small direct economic impact. One exception may be a case intended to establish an important precedent, and thereby deter a great deal of harmful conduct by other firms.

${ }^{42}$ See infra Section IV.D.
} 
that the final VMGs will include explicit reference to them, acknowledge their relevance, and suggest how to analyze them, to preclude giving the misimpression that they are not considered relevant. Discussing these other concerns also can provide useful information to practitioners, courts and agency staff investigating vertical mergers.

- As already discussed, customer foreclosure should be discussed in more detail. This would include the potential interaction between customer foreclosure and input foreclosure.

- The discussion of elimination of potential competition in the dVMGs should be expanded to prevent false negatives and under-enforcement. The final VMGs should explicitly address the competitive harm that arises when a dominant downstream firm acquires a potential competitor into the upstream market whose entry could benefit downstream competition by lowering input prices or increasing input quality. The final VMGs should also explicitly address the possibility that competition would be harmed by the acquisition of (vertical) inputs and complements that can transform into (horizontal) competitors. In tech markets in particular, for example, complements can disintermediate the dominant firm (or support disintermediation) and turn into substitutes, just as a firm might enter at one level and then use that foothold to enter the other market in competition with a vertically integrated dominant firm. ${ }^{43}$

- The final VMGs might also point out, as we previously discussed, ${ }^{44}$ that a horizontal merger between two vertically integrated firms raises foreclosure concerns as well as the usual horizontal merger concerns.

- The dVMGs do not identify the harm to competition that arises when a merger of upstream and downstream dominant firms eliminates the likelihood that either of them would sponsor of entry into the other level. This concern is particularly relevant in platform network markets, which increases the importance of including this issue. ${ }^{45}$

- The dVMGs do not consider the possibility that a merger would permit a regulated merging firm to evade regulatory constraints. Although reliance on price regulation has declined in recent years, this traditional concern about vertical mergers - which was recognized in the 1984 non-horizontal merger guidelines, and was an important basis for the Justice Department's early 1980s case against AT\&T that led to that firm's breakup-

\footnotetext{
${ }^{43}$ See, e.g., Stigler Committee on Digital Platforms Final RePORT 72 (Sept. 2019), https://research.chicagobooth.edu/-/media/research/stigler/pdfs/digital-platforms---committee-report--stigler-center.pdf (Fiona Scott Morton, Chair of the Subcommittee on Market Structure and Antitrust).

${ }^{44}$ Supra text at notes 34 and 35.

${ }^{45}$ Example 5 addresses the possibility that that a vertical merger would discourage entry by requiring a new competitor to enter at two levels, but it does not address the competitive problem we identify here.
} 
is still a concern in some industries. ${ }^{46}$ A similar evasion analysis also would apply when long-term contracts have input cost-based escalators that use input market prices, as illustrated by the following example.

Example H: Suppose that the long-term contracts for jet fuel between airlines and refiners contain a provision that sets the contract price on the basis of the spot price of jet fuel, as cal.culated and published in a respected trade publication. Suppose that after the merger of an airline and a refiner, the refiner begins to make additional spot market purchases that raise the published spot price, and hence raise the contract price paid by the competitors of the downstream merging party. While this type of market price manipulation may not have been profitable before the merger, the gains to the merging airline might make it profitable after the merger.

The final VMGs should address this possibility and evasion of regulation, perhaps with language along the following lines: ${ }^{47}$ "Vertical mergers may facilitate evasion of regulation or the manipulation of long-term contracts with input price escalators. For example, where a downstream affiliate is subject to maximum price regulation dependent on its costs, the upstream affiliate may be able to increase the price of inputs in ways the regulator cannot easily or rapidly detect, and thereby induce the regulator to authorize higher downstream prices. Or, if the merger combines firms that sell complementary products, the merged firm could evade price regulation by increasing the price of the bundle and attributing the price increase to the unregulated product. Similarly, in unregulated markets, where the firms employ long-term contracts for input supply that include price escalation (or de-escalation) provisions that utilize market indices, a vertical merger might permit and provide an incentive for the upstream merging firm to take actions to raise the price escalator in order to raise the costs of the competitors of the downstream merging firm."

\footnotetext{
${ }^{46}$ Evasion of regulation flowing from a vertical merger would not be exempted by Discon. Nynex Corp. v. Discon, Inc., 525 U.S. 128 (1998). That case involved the non-merger conduct of a regulated monopolist and there was not likely a reduction in competition from the alleged fraud. By contrast, if the regulated firm faced competition, then competition would be reduced if unregulated rivals would be expected to accommodate price increases from the regulatory evasion, as by raising their prices too. In addition, the issue before the Court in Discon was whether to apply a per se rule against this type of boycott, not whether regulatory evasion by merger would violate Section 7. Similarly, Trinko involved the question of whether a refusal to deal by a regulated firm would violate Section 2, not whether a merger would violate Section 7. Verizon Commc'ns Inc. v. Law Offices of Curtis v. Trinko, LLP, 540 U.S. 398 (2004).

${ }^{47}$ In addition, the final VMGs might allow regulatory evasion to trigger an anticompetitive presumption under appropriate conditions.
} 
- With the exception of misuse of sensitive competitive information having the effect of reducing competitors' incentives to innovate, the dVMGs appear to focus only on nearterm effects. The final VMGs should recognize, as the DOJ did in AT\&T/Time Warner, that the harm from the merger need not happen immediately for Section 7 to apply. ${ }^{48}$ They may also note that when harms or benefits do not develop for a longer period of time, the analysis may involve uncertainty and time discounting, as explained in a recent speech by AAG Delrahim. ${ }^{49}$

\section{The Profitability Test Should Not Refer to Pre-Merger Profitability}

The unilateral effects section reasonably treats the "profitability" of a foreclosure or raising rivals' costs strategy as potential evidence of the likelihood that such conduct will be implemented. ${ }^{50}$ For example, even if an input price increase would not have been profitable to the unintegrated upstream firm before the merger, the gains to the downstream firm from input foreclosure could make it profitable after the merger and thereby give the merged firm an incentive to undertake that conduct. ${ }^{51}$

However, the language of the dVMGs and some economic commentary suggest that the agencies will not challenge such conduct unless they also find that raising rivals' costs or foreclosure conduct would not have been profitable absent the merger. That is, the draft VMGs read as if a showing of pre-merger unprofitability is another requirement placed on the agencies. In Section 5a, the dVMGs describe a comparison between post-merger and pre-merger profitability as a factor the agencies "may consider." The first paragraph of Section 6 appears to treat the comparison as a requirement with an implicit burden of proof on the agencies.

\footnotetext{
${ }^{48}$ Proposed Conclusions of Law, supra note 6 , at $9 \uparrow 10-13$.

${ }^{49}$ Makan Delrahim, Assistant Att'y Gen., Antitrust Div., U.S. Dep't of Justice, Harder Better Faster Stronger: Evaluating EDM as a Defense in Vertical Mergers, Remarks at George Mason Law Review 22nd Annual Antitrust Symposium 7 (Feb. 15, 2019), https://www.justice.gov/opa/speech/file/1132831/download.

${ }^{50} \mathrm{With}$ respect to the general profitability analysis, we suggest that the final VMGs observe that the profitability of a raising rivals' costs or foreclosure strategy can be presumed when it would be inexpensive to implement (e.g., if the upstream affiliate in the related market can divert sales to unrelated markets without cutting price, or if the margin on foregone sales in the related market is low).

${ }^{51}$ We note that the unprofitability of "total foreclosure" does not imply that input price increases also would be unprofitable. The "vertical arithmetic" methodology of the profitability of "total foreclosure" thus would be an overly permissive test. See Serge Moresi \& Steven. C. Salop, vGUPPI: Scoring Unilateral Pricing Incentives in Vertical Mergers, 79 ANTITRUST L.J. 185, 208-10 (2013).
} 
This interpretation may not have been intended. ${ }^{52}$ But some economists have suggested this type of requirement. ${ }^{53}$ As we discuss below, that requirement does not make economic sense. It also would lead to false negatives and under-deterrence by raising the agencies' burden and by offering the merging firms an inappropriate escape route. Yet it would not reduce false positives. Therefore, any language requiring or suggesting the need for a showing of pre-merger unprofitability should be removed, even as a factor the agencies "may consider."

The suggested inference - that the positive profitability of foreclosure pre-merger would indicate that post-merger competitive harms would not occur - does not make economic sense. If the parties are not acting on anticompetitive incentives before the merger, then that fact should trigger an inquiry into why they are not doing so. It should not trigger an assumption that the anticompetitive theory somehow must be wrong or that the parties are good citizens that can be trusted to protect the interests of consumers.

Suppose the agencies find that the merging firms could have profitably made an exclusionary vertical agreement before (i.e., absent) the merger, but did not do so. This fact does not imply that the parties would lack post-merger anticompetitive incentives or that the merger would lack any anticompetitive effects. For example, the firms might not have made such an anticompetitive agreement before the merger for fear that it would violate Section 1 of the Sherman Act or Section 5 of the FTC Act. If the pre-merger profitability of the agreement is treated as a reason not to challenge the merger, then the firms can use their merger to evade Section 1 or Section 5, if that were the reason the firms did exclude by contract pre-merger. As another example, suppose that one of the merging firms was already vertically integrated but did not engage in foreclosure conduct that the agency concludes would have been profitable before the merger. That does not mean that post-merger foreclosure would not occur. Instead, the explanation for the failure to foreclose in the pre-merger world might be that the firm actually was fearful of some countervailing factor that the agency failed to identify, so that the conduct actually was unprofitable. The proposed new vertical merger might sufficiently increase the profitability such that it overcomes that fear. ${ }^{54}$ If the pre-merger profitability of the agreement is

\footnotetext{
${ }^{52}$ The agencies may have intended merely to point out that a vertical merger may increase profitability of foreclosure on the margin (as when, in the input foreclosure case, downstream rivals divert sales to the merged firm), and that the magnitude of this incremental benefit would be considered. If that is the point, our comments should be understood as recommending that the point be clarified to prevent a pernicious misreading.

${ }^{53}$ See Dennis Carlton \& Bryan Keating, Rethinking Antitrust in the Presence of Transaction Costs: Coasian Implications 46. REV. INDUS. ORG. 307, 311-13 (2015).

${ }^{54}$ For example, the upstream firm might have faced commitment problems that would be resolved by vertical integration. See Patrick Rey \& Jean Tirole, A Primer on Foreclosure, in 3 HANDBOOK OF INDUSTRIAL ORGANIZATION 2145 (Mark Armstrong \& Robert H. Porter, eds., 2007).
} 
treated as a reason not to challenge the merger, the firms can exploit the agencies' information disadvantage to harm competition. ${ }^{55}$

Finally, a focus on comparing pre-merger and post-merger profitability will inevitably have adverse effects on the incentives of potential merging parties. It will give the firms an incentive to temporarily forego profitable exclusionary conduct in order to justify and immunize a subsequent anticompetitive vertical merger.

\section{Quantification Should Not be Required}

While the point is not stated explicitly and may not have been intended, the dVMGs can be interpreted as suggesting that quantification of harms and benefits by the agencies generally will be required. ${ }^{56}$ The final VMGs should be clarified to avoid that suggestion by explicitly rejecting a requirement to quantify the potential harms and benefits of a vertical merger in order to evaluate its competitive effects.

While quantification can at times be informative, there are several reasons to disclaim a general quantification requirement in the final VMGs. It is not required by the courts, ${ }^{57}$ and it is not consistent with the way that the enforcement agencies understand Section $7 .^{58}$ In addition, requiring quantification of competitive harms and profitability will unnecessarily and inappropriately raise the agency's practical burden for enforcement and in cases that go to court.

As a general matter, it should be recognized that requiring quantification of competitive harms through data analysis and simulation modeling raises the agency's practical burden. Such a requirement also may create an impression that those issues for which the economics profession has developed the most precise quantification methods are somehow more important or more harmful than other issues, which is not the case. Requiring quantification in every case can have the practical effect of limiting competitive concerns only to those effects that can be evaluated using the available data and methods developed by academic economists to the exclusion of

\footnotetext{
${ }^{55}$ It might be suggested that the agencies wait to see if the foreclosure would occur. Such a policy would open the door to serious competitive harms, however. First, the post-merger foreclosure might not be detected. Second, the foreclosure might not violate Section 2 of the Sherman Act because it would be carried out by a single, vertically integrated entity, or because the merged firm may not have a market share sufficiently high to meet the standards many courts employ to identify monopoly power or dangerous probability of success of monopolization. Third, even a successful Section 2 case were brought, there would be substantial harm to buyers of the downstream product during the pendency of the litigation. Fourth, if the foreclosed rivals have exited, remedial choices may be limited.

${ }^{56}$ The dVMGs discuss simulation models in the second paragraph of the unilateral effects section. Evaluation of the potential profitability of foreclosure, which is frequently alluded to in the dVMGs, also seems to require substantial and detailed quantification.

${ }^{57}$ E.g., United States v. AT\&T, Inc., 916 F.3d 1029, 1045 (D.C. Cir. 2019) (“[T]he court does not hold that quantitative evidence of price increase is required in order to prevail on a Section 7 challenge.").

${ }^{58}$ E.g., Proposed Conclusions of Law, supra note 6, at $\uparrow \uparrow 14-16$.
} 
other important concerns. ${ }^{59}$ Thus, a quantification requirement would discourage the agencies from challenging anticompetitive mergers that raise significant problems that are evident from ample theoretical, documentary, and testimonial evidence, ${ }^{60}$ or competitive problems that cannot be evaluated quantitatively.

If courts interpret the final VMGs as implying that quantification of harms by the agency should be required in litigation, problems like these will make it more difficult for the government to prevail when bringing meritorious cases, thereby reducing the agencies' incentive to bring such cases and, in consequence, increasing the likelihood that firms will propose anticompetitive vertical mergers and convince the agencies not to challenge them. ${ }^{61}$

\section{Section 6: Elimination of Double Marginalization}

The potential competitive benefits from vertical mergers include both the elimination of double marginalization ("EDM") and other efficiency benefits from better coordination between the merging firms. However, this Section does not belong in the middle of the discussion of competitive harms. We recommend that EDM be treated the same way as other efficiencies and that this section be incorporated into the efficiencies discussion (Section 8). We have serious concerns that the current approach will lead to under-enforcement for a number of reasons.

\section{A. EDM Should Be Treated in the Same Way as Other Efficiencies}

We are very concerned that the treatment of EDM will inappropriately lower the burden on the parties and raise the burden on the agencies (or private plaintiffs), and thus lead to false negatives and under-enforcement. We reach this conclusion for two related reasons.

First, in the input foreclosure case that the dVMGs emphasize, for example, the benefits of EDM come from taking into account the impact of the upstream margin on the downstream price for the input produced by the upstream affiliate. ${ }^{62}$ Those allocative efficiency benefits are derived from coordinating the incentives of the upstream and downstream firm. Moreover, the EDM discussion is sandwiched between two competitive harms sections rather than following them.

\footnotetext{
${ }^{59}$ Development of new methods in empirical economics unfortunately often progresses in a way is not driven by policy relevance. It does not serve consumer interests to tie enforcement intensity to that imperfect process.

${ }^{60}$ Requiring quantitative evidence may have the practical effect of discouraging reliance on qualitative evidence, even when the qualitative evidence is more informative than quantitative evidence.

${ }^{61}$ A court may have substantially less expertise than the agencies in evaluating controversies about empirical analysis, and may not do so as effectively as the agencies. A district court may not have the time to hear and evaluate quantitative evidence and associated criticisms. Data imperfections that might be properly vetted during the HSR process might not be so in the time frame of a short trial.

${ }^{62} \mathrm{EDM}$ allows downstream affiliate to purchase the input at the upstream firm's marginal cost rather than with a markup, or otherwise provide incentives for the downstream firm to reduce its price, ceteris paribus.
} 
This is illogical in that analysis of all types of allocative efficiencies, EDM included, also is relevant to coordinated effects concerns. We also are concerned that this treatment will suggest to the parties and a court that the agencies must demonstrate the extent (or lack) of EDM, rather than placing the burden of producing evidence of cognizable EDM on the merging firms, where it belongs.

Second, the dVMGs' treatment of EDM will lead to under-enforcement because the text does not appear to require the parties to show that the EDM efficiencies are "cognizable," that is, mergerspecific, verifiable, and not the product of anticompetitive conduct. The dVMGs recognize that the benefits of EDM are low when the firms previously partially eliminated doublemarginalization contractually. ${ }^{63}$ But this section does not make clear that EDM claims must always be tested for merger-specificity. Nor does it clearly place the burden of proving this on the merging firms, despite the fact that this is DOJ policy and its view of the law. ${ }^{64}$ Instead, the dVMGs merely state that "[t]he agencies generally rely on the parties to identify and demonstrate whether and how the merger eliminates double marginalization." This language ("generally rely on the parties") could be interpreted as saying that the parties' claims will be accepted as true and then the agencies themselves will be required to rebut them, not that the burden will be placed squarely on the parties. (As with the profitability test language previously discussed, this interpretation of the language may not have been intended.) To dispel confusion, the final VMGs should state explicitly that the evaluation of EDM requires addressing the same questions and evidence of cognizability (i.e., merger-specificity, verifiability, and not arising from output reductions) and pass-through that are addressed when evaluating other types of efficiencies and used in the HMGs, with the burden of providing evidence proof placed on the merging firms.

We also want to comment on the common assumptions that EDM merger benefits are inevitable, that a failure to achieve EDM benefits in the pre-merger market is sufficient proof that EDM would occur post-merger, and that EDM can be presumed to be merger-specific and otherwise cognizable. Economic reasoning does not support these assumptions and, therefore, we recommend that the final VMGs should make the point that they would be unwarranted.

We also recommend that the final VMGs include discussion of the various specific reasons why the potential for EDM may not lead to consumer benefits. These reasons are important because absent merger-specific EDM, the downstream merging firm would have the incentive to raise

\footnotetext{
${ }^{63}$ The dVMGs state that the "effects of the elimination of double marginalization may be lower if, prior to the merger, the merging parties already engaged in contracting that aligned their incentives, for example by using a two-part tariff with a fixed fee and low unit prices that incorporate no, or a small, margin."

${ }^{64}$ In AT\&T/Time Warner, DOJ explained, citing D.C. Circuit precedent, that efficiencies must be subject to "rigorous analysis," with the burden placed on the merging parties. Proposed Conclusions of Law, supra note 6, at PCOL $9993-99$. It did not draw a distinction between EDM and other efficiencies. See id. at 9179,99 . See also Delrahim, supra note 49, at 7-8.
} 
price unilaterally. ${ }^{65}$ In fact, this incentive can occur even aside from incentive to raise price that flows from input foreclosure. ${ }^{66}$ This incentive is the driving force of the point made in the dVMGs that "if the merged firm raises its price in the downstream market, downstream rivals may increase their sales, which could increase their demand for inputs from the merged firm's upstream business. Capturing this benefit through merger may make the downstream price increase more profitable." 67

First, EDM may not be achieved by the merger for a number of reasons, some but not all of which are noted in the EDM section of the dVMGs. ${ }^{68}$ These include the following:

- As noted in the dVMGs, the downstream merging firm may not acquire inputs from the upstream merging firm because of input incompatibility. ${ }^{69}$ Internal supply may not be efficient for a number of other reasons too. ${ }^{70}$ Empirical evidence from a large data base of vertically integrated firms indicates there were no internal input transfers from the upstream division to the downstream division in about half of all the vertically-integrated firms studied. ${ }^{71}$

- EDM would be minimal and would not offset the unilateral incentive to raise price if there is substantial pre-merger competition among upstream firms or commitment impediments that lead to a low upstream profit margin earned by the upstream merging firm on sales to the downstream merging firm. ${ }^{72}$

\footnotetext{
${ }^{65}$ Moresi \& Salop, supra note 51, at 198.

${ }^{66}$ For further analysis, see Moresi \& Salop (Comment), supra note 5 at n.36; Yongmin Chen, On Vertical Mergers and Their Competitive Effects, 32 RAND J. ECON. 667 (2001).

${ }^{67}$ U.S. Dep't of Justice, supra note 1, at 7.

${ }^{68}$ For a similar but not identical list, see John Kwoka \& Margaret Slade, Second Thoughts on Double Marginalization, ANTITRUST (Spring 2020) (forthcoming), https://papers.ssrn.com/sol3/papers.cfm?abstract_id=3452207.

${ }^{69}$ See id.

${ }^{70}$ In addition to the upstream firm's inputs being incompatible with the technology of the downstream firm, the downstream firm may be locked-in to a long-term contract or there may be other switching costs. It is also possible that the plants are not located close to one another and the transportation costs to deliver the inputs to the downstream firm may be high. The upstream firm also may have limited capacity that can be switched over to the downstream firm.

${ }^{71}$ Enghin Atalay, Ali Hortaçsu \& Chad Syverson, Vertical Integration and Input Flows, 104 AM. ECON. REV. 1120, 1127 (2014).

${ }^{72}$ See Janusz A. Ordover, Garth Saloner \& Steven C. Salop, Equilibrium Vertical Foreclosure, 80 AM. ECON. REV. 127 (1990) (pre-merger competition); Oliver Hart \& Jean Tirole, Vertical Integration and Market Foreclosure, 21 BROOKINGS PAPERS ON ECONOMIC ACTIVITY (MICROECONOMICS) 205 (1990) (commitment issues).
} 
- In the pre-merger market, the upstream merging firm may have engaged in strategic pricing (i.e., not simply unilateral pricing incentives) that involved a high input price rather than achieving EDM (e.g., with a two-part tariff or other contractual provision) out of a fear that the low prices might spread to other firms and lead to lower market prices across-the-board, rather than higher margins for the parties. This same concern would carry over after the merger and could be magnified if downstream margins also would fall.

- As noted in the dVMGs, the upstream merging firm might have less incentive to reduce downstream prices to achieve increased sales of the input to the downstream firm because it would result in the loss of profitable input sales to rivals of the downstream competitors, since some of their customers would divert to the downstream merging firm. ${ }^{73}$ This limitation on EDM is particularly important when downstream demand is inelastic. $^{74}$ The dVMGs recognize that this factor may make post-merger downstream price increases more profitable. ${ }^{75}$

- The upstream merging firm similarly might have less incentive to reduce downstream prices for sales of the input to the downstream firm if the higher sales result in the loss of profitable sales to customers outside the relevant downstream market. This can occur if the firm faces limited capacity or rising marginal costs, which also would reduce or eliminate EDM incentives to reduce price.

- The input may be a "fixed" rather than a "variable" input for the downstream merging firm. For example, the input may be access to the technology of the upstream firm that is sold on a fixed cost basis or access to updates that had previously been provided to all previous purchasers of the technology. If the downstream firm already has acquired access, there would be no EDM. But, denying new entrants' access to the technology could deter entry and foreclosing access to updates could raise rivals' costs.

- As noted in the dVMGs, the merging firms may have substantially reduced or eliminated double marginalization in their pre-merger contract by the use of complex contractual provisions such as volume discounts, take-or-pay provisions, or two-part tariffs. ${ }^{76}$

\footnotetext{
${ }^{73}$ In economic terms, this is referred to as a high opportunity cost.

${ }^{74}$ See Moresi \& Salop, supra note 51, at 199.

${ }^{75}$ See U.S. Dep't of Justice, supra note 1, at 7, as quoted in text supra at note 67 ( "if the merged firm raises its price in the downstream market, downstream rivals may increase their sales, which could increase their demand for inputs from the merged firm's upstream business. Capturing this benefit through merger may make the downstream price increase more profitable.")

${ }^{76}$ The dVMGs explain that the "effects of the elimination of double marginalization may be lower if, prior to the merger, the merging parties already engaged in contracting that aligned their incentives, for example by using a two-part tariff with a fixed fee and low unit prices that incorporate no, or a small,
} 
- While we economists normally and appropriately assume that a vertically integrated firm will act as a unitary entity that maximizes joint profits, in some cases, a firm may not instruct the downstream division to favor the upstream division in its purchasing behavior or to take EDM into account in its own pricing. ${ }^{77}$ This decentralization may be adopted, for example, in order to simplify compensation formulae and decision-making by the managers in each division. ${ }^{78}$

- As is the case for all efficiencies, the downward pricing pressure from the EDM may not fully offset the increased pricing pressure from the foreclosure, so consumers would be harmed on balance, as noted in the efficiencies section of the dVMGs. ${ }^{79}$

Second, in situations where these conditions may not apply, so that there is the potential for postmerger EDM, the parties also should be required to show that this efficiency benefit is mergerspecific. EDM may or may not be merger-specific and that fact should not be presumed.

Economists have recognized for decades that vertical efficiencies sometimes may be achieved by contract. ${ }^{80}$ The parties must be required to produce evidence that the merger eliminates the barriers to realizing EDM and that these barriers could not be eliminated in any practical way absent the merger.

Moreover, the merging firms should be required to explain the specific impediments that prevent them from achieving the EDM efficiencies by contract. It is not enough to state that there were "bargaining frictions." All negotiations involve bargaining frictions, including negotiations within the post-merger firm. As we said in our previous article, a claim that there were

margin." U.S. Dep't of Justice, supra note 1, at 7. However, two-part tariffs are not the only way to eliminate EDM by contract. We recommend that the final VMGs also explicitly identify examples of additional contractual provisions that the firms could employ to do so, such as quantity-driving provisions (e.g., take-or-pay provisions) or volume discounts.

${ }^{77} \mathrm{Cf}$. Paul Milgrom \& John Roberts, Economics, Organization and Management 549-52 (1992) (discussing reasons upstream divisions might not transfer inputs to downstream divisions at the best price for corporate profit-maximization). As we discuss in Section VI.B, this possibility does not imply that there could be no raising rivals' costs effects from the merger.

${ }^{78}$ Potentially relevant evidence could include the following: analysis of the track record of corporations when one of its products uses inputs that may be produced by another division; the track record in pricing when the firm sells multiple substitute or complementary products (which raises similar issues); ordinary course documents regarding this or other potential acquisitions before the lawyers and economic consultants became involved in the transaction; analysis of actual or potential inter-corporate transfers or pricing incentives when one of firms is owned by a private equity firm that sells substitutes, complements or vertically related products.

${ }^{79}$ See U.S. Dep't of Justice, supra note 1, at 9.

${ }^{80}$ Ronald H. Coase, The Nature of the Firm, 16 ECONOMICA 386 (1937); Sanford J. Grossman \& Oliver Hart, The Costs and Benefits of Ownership: A Theory of Vertical and Lateral Integration, 94 J. POLITICAL ECONOMY 691 (1986). 
"bargaining frictions" is inadequate, just as it would not be considered sufficient evidence of merger-specificity in horizontal merger cases. ${ }^{81}$ To mirror Robert Bork's famous remark about vertical restraints, ${ }^{82}$ if the parties' only reason for failing to achieve EDM is bargaining frictions, the enforcement agencies would do better by introducing the parties to a top-notch mediator or arbitrator rather than permitting an otherwise potentially anticompetitive merger. ${ }^{83}$

Third, those impediments that are the result of anticompetitive agreements or motives also should not be credited. For example, if the pre-merger impediment was the fear that achieving EDM by contract would eliminate upstream coordination by upstream competitors, that impediment should not be considered cognizable. As one illustration, in the case of AT\&T/Time Warner, the most obvious barrier to achieving EDM absent the merger may have been MFNs that prevented discounting. ${ }^{84}$ If so, the MFNs themselves were anticompetitive. Had the parties not engaged in such an anticompetitive practice pre-merger, they could have negotiated contracts that eliminated double marginalization without needing to merge to do so.

\section{B. Erroneous Arguments for Treating EDM as Part of Competitive Harm Should Not Be Credited}

The dVMGs do not explain why they have placed the discussion of EDM into the competitive harm section rather than the efficiencies section. We are concerned that this placement might reflect various erroneous economic and policy arguments.

Before discussing these erroneous arguments, we want to stress a preliminary point. There is no disagreement that analysis of the significance of EDM should be undertaken when competitive effects are evaluated (along with the competitive consequences of other marginal cost reductions), and that feedbacks among the various effects should be considered in doing so, if and when the EDM is shown to be cognizable. But we are concerned that the placement of the EDM section discussion within the harm section of the dVMGs (i.e., between the sections on unilateral and coordinated harms) will obscure the fact that the antitrust defendant has the burden of establishing that these efficiency claims are cognizable. ${ }^{85}$

\footnotetext{
${ }^{81}$ Baker et. al. supra note 2 at 15 . We noted that the agencies likely would not consider merger-specific a claim that the merger would eliminate a patent royalty or would allow the firms to settle their ongoing patent infringement litigation by eliminating bargaining frictions.

${ }^{82}$ Robert H. Bork, The Antitrust Paradox: A Policy at War With ItSElf 232 (1978).

${ }^{83}$ In an analogous bargaining setting, most lawsuits settle. It is very rare for large firms involved in a lawsuit to settle the suit by merging.

${ }^{84}$ See Erik Hovenkamp \& Neel Sukhatme, Vertical Mergers and the MFN Thicket in Television, ANTITRUST CHRONICLE (2018), https://www.competitionpolicyinternational.com/wpcontent/uploads/2018/08/CPI-Hovenkamp-Sukhatme.pdf; Salop, supra note 40, at 468.

${ }^{85}$ The defendant has the initial burden to show that efficiencies would prevent an otherwise anticompetitive price increase in merger analysis under Section 7 of the Clayton Act, and more generally in all cases
} 
There are several erroneous arguments that might improperly be thought to justify including EDM in the competitive harms section.

First, some have suggested that EDM must be considered directly as part of the competitive effects analysis - and thus put an initial burden on the agencies to show the magnitude of EDM - because, it is claimed, incentives to raise rivals' costs and EDM are inherently related. In particular, the argument goes, when incentives to raise rivals' costs are substantial, the benefits of EDM also must be substantial. ${ }^{86}$ This "symmetry" argument is flawed, and the implication that EDM must be analyzed as part of the agency's initial evaluation of competitive effects is erroneous, for several reasons.

- This argument improperly assumes that EDM is merger-specific, whereas that may not be the fact and instead is a threshold question. As discussed above, Coase's seminal article and others explain how contracts are often a substitute way to achieve vertical efficiencies. ${ }^{87}$ This is not to say that EDM or other efficiencies can always be achieved by contract. Instead, we are making the point that one cannot assume away the mergerspecificity issue by alluding to economic models.

- The symmetry argument is based on a class of economic models that involve both linear tariffs for input purchase and then some type of symmetric linear contract to raise rivals' costs. As a matter of economic theory, this argument assumes one particular type of economic model out of many, in which incentives to raise rivals' costs are high and the benefits of EDM also are substantial, but that type of model often will not apply.

- The assumption specifically ignores other plausible and well-recognized models in which the benefits of EDM are low when incentives to raise rivals' costs are high. For example, this could occur in an input foreclosure setting in which multiple upstream firms compete intensely in the pre-merger world and the non-merging upstream firms would accommodate post-merger upstream price increases by the merging firm by raising their own prices. ${ }^{88}$ Little or no EDM benefits also coexist with significant raising rivals' costs

\footnotetext{
analyzed under the rule of reason, including horizontal restraints and vertical restraints. This includes wellknown cases evaluating exclusionary vertical restraints. Leegin Creative Leather Prod., Inc. v. PSKS, Inc., 551 U.S. 877 (2007); United States v. Microsoft Corp., 253 F.3d 34, 59 (D.C. Cir. 2001); McWane, Inc. v. FTC, 783 F.3d 814, 833 (11th Cir. 2015); ZF Meritor, LLC v. Eaton Corp., 696 F.3d 254, 281-82 (3d Cir. 2012). There is no reason to deviate from this approach for vertical mergers reviewed under Section 7.

${ }^{86}$ Daniel O'Brien, Fed. Trade Comm'n Hearings: Competition and Consumer Protection in the 21st Century, Transcript 40 (Nov. 1, 2018), https://www.ftc.gov/system/files/documents/public_events/1415284/ftc_hearings_session_5_transcript_1 1-1-18.pdf. See also Joseph J. Spengler, Vertical Integration and Antitrust Policy, 58 J. POL. ECON. 347 (1950).

${ }^{87}$ Coase, supra note 80 ; Grossman \& Hart, supra note 80.

${ }^{88}$ Ordover et al., supra note 72.
} 
incentives in Hart and Tirole's seminal bargaining model of vertical merger incentives. ${ }^{89}$ EDM benefits also may be low while the merger leads to substantial price increase at either level if the vertical merger leads to coordinated effects, either from eliminating mavericks or disruptive buyers, or from facilitating information exchanges.

- The assumption also ignores the possibility, discussed above in Section VI.A, that the upstream firm was engaged in strategic pricing and the merged firm may fear that lower prices from EDM would lead to lower market prices across-the-board, rather than higher margins for the merged firm.

- Raising rivals' costs incentives are also independent of the benefits from EDM when the upstream merging firm does not supply the downstream firm with inputs. As noted above, this internal supply often does not occur. ${ }^{90}$

- The assumption that EDM benefits are correlated with raising rivals' costs incentives also ignores an implication of an effect identified in the dVMGs: EDM benefits might be low in an input foreclosure setting in which the downstream merging firm raises prices, shifting demand to downstream rivals that increase their demand for inputs purchased from the upstream merging firm. ${ }^{91}$

In short, the economics literature does not support the proposition that there is a reliable relationship between EDM and raising rivals' cost (or total foreclosure), and thus provides no basis for relying on a purported relationship to require the agencies to analyze EDM as part of their initial burden to evaluate competitive harm.

Second, a related attempt to shift the burden of showing efficiencies onto the agencies is the argument that EDM is not an "efficiency" because it involves a procompetitive internalization of incentives, not a resource cost reduction or quality increase. Although EDM is not a cost reduction, it is an allocative efficiency benefit and that is how it normally is treated. ${ }^{92}$ That is also how other procompetitive incentive effects are treated in antitrust law. For example, elimination of free riding as a result of resale price maintenance or other vertical restraints is also an incentive effect, but it is treated as an (allocative) efficiency benefit in Leegin. ${ }^{93}$ The key economic point is that these are all sources of "competitive benefits" of the merger that create

\footnotetext{
${ }^{89}$ Hart \& Tirole, supra note 72.

${ }^{90}$ Atalay et al., supra note 71, at 1127.

${ }^{91}$ U.S. Dep't of Justice, supra note 1, at 7 ("[I]f the merged firm raises its price in the downstream market, downstream rivals may increase their sales, which could increase their demand for inputs from the merged firm's upstream business. Capturing this benefit through merger may make the downstream price increase more profitable.").

${ }^{92}$ See, e.g., Dennis W. Carlton, Mark A. Israel \& Allan L. Shampine, Lessons from AT\&T/Time Warner, ANTITRUST CHRON. 1, 4 (2019) (terming EDM an "efficiency effect"); Dennis W. Carlton, Comment, 21 BROOKINGS PAPERS ON ECONOMIC ACTIVITY (MICROECONOMICS) 277, 279-80 (1990).
}

${ }^{93}$ Leegin Creative Leather Prod., Inc. v. PSKS, Inc., 551 U.S. 877, 878 (2007). 
downward pricing pressure and thereby can mitigate or reverse the upward pricing pressure from the "competitive harms."

Third, another tangentially related argument involves the potential that decentralization by a vertically integrated firm that compensates each division on the basis of its own profits would eliminate both EDM benefits and incentives for raising rivals' cost or total foreclosure. As noted earlier, economists normally and appropriately assume that a vertically integrated firm will act as a unitary entity that maximizes joint profits, not the profits of each individual division separately and independently. However, in some cases, a firm may instruct the downstream division not to favor the upstream division in its purchasing behavior and also instruct it not to take EDM into account in its own pricing. Such a policy would not necessarily imply that the upstream division would be unable to exercise bargaining leverage over the competitors of the downstream merging firm. This is because a firm can be decentralized along one dimension but not another. Thus, while joint profit maximization should be presumed, the implications of decentralization should remain a fact issue in a merger investigation.

\section{Section 7: Coordinated Effects}

This section lists several potential anticompetitive coordinated effects, including elimination of a maverick competitor of the merging firm through foreclosure as well as information exchange. However, the dVMGs do not identify a number of other potential competitive concerns that involve coordination. Stating them explicitly would provide useful information to courts, practitioners and agency staff investigating vertical mergers. This information would help to reduce the likelihood of under-enforcement.

The following possible concerns are not included.

- Foreclosure of mavericks is mentioned but in an incomplete way. The dVMGs provide the example of the vertical merger disadvantaging a non-merging firm that is a maverick, perhaps through input foreclosure. But a vertical merger also can change the competitive incentives of a merging party that previously had been acting as a maverick or disruptive buyer of the input. ${ }^{94}$

- The dVMGs also do not include the case of a non-merging firm that has been a disruptive buyer of the input, and might be neutralized by input foreclosure.

\footnotetext{
${ }^{94}$ For example, suppose a small input supplier acts as a maverick, constraining more effective coordination in a relevant input (upstream) market. If the maverick supplier merges with a large manufacturer (which produces the related product), the merged firm may recognize that its downstream manufacturing business benefits if its manufacturing rivals pay more for the input, leading those rivals to reduce their output or otherwise compete less aggressively. The merged firm may no longer have an incentive to constrain coordination among other suppliers, so wholesale prices for the input may increase. If downstream prices also would be expected to increase from this conduct, the merger also would harm competition in the downstream relevant market.
} 
- The dVMGs do not note that foreclosure also might facilitate coordination downstream by increasing parallel vertical integration that might lead to more symmetric incentives. ${ }^{95}$

- The dVMGs mention that EDM can reduce the likelihood of coordination. But they do not mention that EDM instead may facilitate anticompetitive coordination by increasing symmetry, when competitors in a concentrated market also are integrated. ${ }^{96}$

\section{Section 8: Efficiencies}

The analysis of efficiencies in this section follows the approach of the HMGs by recognizing that a merger may have the potential to create cognizable efficiencies that benefit competition and consumers. We have several comments and recommendations involving this section.

First, we recommend that the types of potential efficiencies be listed in more detail, just as we recommend that potential competitive harms be described more fully.

Second, as noted earlier, we recommend that the analysis of EDM should be incorporated into Section 8 , rather than treated as part of the evaluation of competitive harm.

Third, the dVMGs compare the efficiencies achieved by merger to those that would be achieved by "arm's length" contracts. We recommend that the final VMGs should also recognize the possibility that it might be practical to achieve comparable efficiencies through limited joint ventures short of merger that raise significantly lower or no competitive concerns.

Fourth, the VMGs should note that significant cognizable vertical efficiencies may not occur. There are numerous examples of failed vertical mergers, and vertical mergers can lead to significant management integration problems which can limit the achievement of efficiencies. ${ }^{97}$

Fourth, we recommend that the final VMGs explain how some claimed efficiencies might be accompanied by conduct that raises the cost or reduces the quality or innovation of competitors. For example, a vertical merger that leads the downstream merging firm to gain earlier access to the innovative new products of the upstream firm often would be accompanied by absolute (not simply relative) delays in making those products available to downstream competitors.

\footnotetext{
${ }^{95}$ For example, one count of the DOJ's complaint in AT\&T/Time Warner involved the likelihood of anticompetitive coordination between AT\&T and Comcast. Complaint at 99 , United States v. AT\&T Inc., 310 F. Supp. 3d 161 (D.D.C. 2018) (No. 1:17-cv-02511). The vertically integrated firms may also engage in reciprocal input sales at high prices with MFNs in order to facilitate successful anticompetitive coordination. For further details, see Salop, supra note 2, at 1977-78.

${ }^{96}$ The DOJ alleged this type of coordinated effect would arise from the Premdor/Masonite merger. United States v. Premdor, Inc., No. 1:01CV01696, 2002 WL 1816981 (D.D.C. Apr. 5, 2002).

${ }^{97}$ In economic terms, there can be Coasian transactions costs within a firm which can limit the efficiencies from vertical mergers, including EDM. See also John Stuckey \& David White, When and When Not to Vertically Integrate, MCKINSEY QUARTERLY (1993), https://www.mckinsey.com/businessfunctions/strategy-and-corporate-finance/our-insights/when-and-when-not-to-vertically-integrate.
} 
Fifth, the dVMGs state that they will follow the approach to efficiencies in the HMGs. Analysis of efficiencies in vertical mergers can raise issues involving out-of-market efficiencies that we recommend the agencies address. In particular, the competitive harm might occur in one relevant market while the efficiency benefits might occur in the other relevant market or in the supply of a related product. For example, in the case of customer foreclosure or coordination in the upstream market, the competitive harms may occur in the upstream market but there may be efficiency benefits in the downstream market such that the customers of the downstream firms may not be harmed or might even be benefited. ${ }^{98}$

When there are harms in an upstream relevant market, but efficiency benefits that potentially can lead to offsetting downward pricing pressure in the downstream market, the HMGs would treat these benefits as out-of-market efficiencies that are not cognizable under the usual Philadelphia National Bank standard, or it would treat them as "inextricably linked" efficiencies subject to agency's "prosecutorial discretion." While the dVMGs state that the agencies will follow the HMGs, we recommend that the agencies make its approach explicit and identify relevant scenarios. Some practitioners and commentators may expect or prefer a different approach. ${ }^{99}$

\section{Remedy}

The dVMGs, like the HMGs, do not discuss remedy. We suggest that some type of guidance on remedies might be useful, whether contained in the VMGs or in a separate document. In particular, it would be helpful for the agencies to address an issue raised in the AT\&T/Time Warner litigation: whether the agencies will consider unilateral remedies developed by the merging firms in the competitive effects analysis, and whether they believe courts should or should not do so. For example, these unilateral remedies might involve contracts entered into by the merging firms with suppliers or customers purporting to prevent competitive harm, for example, by guaranteeing that prices will not rise. The guidance could usefully discuss the significance of finite contract duration, the difficulty in preventing all types of possible anticompetitive conduct through contract, and how to tell whether a contract that partially protects one entity from a merger's full anticompetitive effects for a limited period of time would be sufficient to resolve an agency's concern about the transaction overall.

\footnotetext{
${ }^{98}$ Our Example G involved harm in separate downstream markets in which the downstream merging firm does not compete. There also could be harms in multiple relevant markets but benefits in only one. For example, if the customer foreclosure leads to input foreclosure, there could be harm in both the upstream (input) relevant market and the downstream (output) relevant market. Similarly, if the vertical merger leads to harms from coordination in the upstream market, for example, by eliminating a disruptive buyer or upstream maverick, or from information exchanges, there also could be harms either solely in the upstream market or in both markets. The VMGs also should say explicitly that when there may be competitive harms in both markets, the agencies will identify and evaluate both of them.

${ }^{99}$ See, e.g., Wong-Ervin, supra note 23.
} 


\section{Conclusions}

In many respects, the $\mathrm{dVMGs}$ reflect modern economic thinking about vertical mergers. The agencies are to be congratulated for this step forward. We particularly commend the dVMGs for correctly declining to accept invitations to provide vertical mergers with a procompetitive presumption that would raise the agencies' practical burden of proof.

But the gaps in coverage and a number of features of the dVMGs raise serious prospects of false negatives and under-enforcement, which can be demonstrated by reference to existing economic tools and models. As we mentioned earlier, our greatest concerns besides the gaps in coverage involve four issues: (i) the treatment of the EDM, particularly that the dVMGs appear inappropriately to allocate proof of cognizability to the agencies burden and inappropriately treat the merging firm's failure to have eliminated double marginalization pre-merger as proof that the merger would lead to EDM and that the post-merger EDM would be merger-specific; (ii) the seemingly arbitrary and inappropriately permissive safe harbor; (iii) the inappropriate (though perhaps unintended) apparent requirement that harms be quantified; and (iv) the inappropriate (though perhaps unintended) apparent requirement that the agencies show that foreclosure would not have been profitable before the merger.

We appreciate the opportunity to comment on the current draft, and we hope the agencies will take our criticisms as constructive and adopt our recommendations for revising the dVMGs to address the issues and problems we have identified. These revisions are necessary to implement a modern and effective vertical merger policy. 